\title{
LAS ESTRATEGIAS DE CRECIMIENTO DE LA INDUSTRIA QUÍMICA ALEMANA EN ESPAÑA, 1880-1936: EXPORTACIÓN E INVERSIÓN DIRECTA *
}

\author{
NURIA PUIG \\ Universidad Complutense de Madrid \\ JAVIER LOSCERTALES \\ Friedrich Engels Gymnasium, Berlín
}

\section{RESUMEN}

En este trabajo se reconstruyen y examinan las dos grandes estrategias de crecimiento de las empresas químicas alemanas en España entre 1880 y 1936: la exportación y la inversión directa. Ambas fueron, en todo el mundo, importantes vías de transferencia tecnológica, especialmente después de la Primera Guerra Mundial. Para averiguar por qué en la industria química espanola los efectos modernizadores del primer inversor mundial fueron tan escasos, se abordan dos tareas: 1) valorar la estrategia de las firmas alemanas en España a la luz de las desplegadas en todo el mundo, y 2) analizar las medidas que las empresas y la Administración españolas aplicaron para defender el mercado nacional y fomentar el surgimiento y la consolidación de la industria química española.

N. de E.: Fecha de recepción en la Revista de Historia Económica: marzo, 2000.

Fecha de aprobación por el Consejo de Redacción: diciembre, 2000.

* Muchas personas nos han brindado sus ideas y opiniones en el curso de las inves. tigaciones que han dado lugar a este trabajo conjunto, en particular Peter Hertner (Universidad de Halle) y los participantes en el proyecto europeo «The Evolution of Chemistry in Europe, 1789-1939" y en el proyecto de la DGES «La gran empresa en España», dirigido por Albert Carreras (Universitat Pompeu Fabra). El personal de los archivos, públicos y privados, en los que hemos trabajado se ha mostrado siempre cooperativo y ocurrente. Dos evaluadores anónimos, por último, han hecho sugerencias de gran interés. Todos ellos merecen nuestro agradecimiento, pero no compartir nuestros errores, por supuesto. 


\section{ABSTRACT}

This paper reconstructs and examines the growth strategies displayed by the German chemical industry in Spain between 1880 and 1936: exports and direct investment. Elsewhere both became instrumental for the transfer of technology and managerial skills, particularly after World War I. In order to understand why the effects of the first world chemical investor were so poor on the Spanish industry, the German strategies are analyzed in the light of those followed elsewhere. Furthermore, those policies applied both by the Spanish firms and Administration to encourage the rise and development of the local industry are also examined.

\section{INTRODUCCIÓN}

La industria química española ha sido durante la segunda mitad del siglo $\mathrm{xx}$ uno de los sectores más dinámicos de la economía española, apoyando de forma decisiva la industrialización definitiva del país. España es además hoy el octavo país productor químico del mundo, y registra uno de los ritmos de crecimiento más elevados de Europa. Sin embargo, el paisaje empresarial de la química española continúa, como hace un siglo, dominado por las firmas de los países más industrializados. De las multinacionales presentes en España destacan las alemanas. Éstas, como en casi todo el mundo, llegaron a nuestro país en las últimas décadas del XIX. Gracias a las capacidades científicas, técnicas y comerciales desarrolladas en los campos más modernos de la química, no tardaron en alcanzar posiciones dominantes en los mercados de exportación. La fabricación a gran escala de colorantes, productos farmacéuticos y fotoquímicos y fertilizantes de síntesis, estaba provocando reducciones de precios espectaculares. Dado lo limitado del mercado alemán, los fabricantes no tardaron en cerrar acuerdos para regularlo a través de las llamadas convenciones, así como en orientarse plenamente al exterior. Desde los países clientes de la química alemana apenas se ofrecía resistencia, a pesar de que algunos de ellos, como Gran Bretaña o Francia, contaban con una tradición notable y eran competitivos en otros campos de la química industrial.

Pero la Gran Guerra alteró este estado de cosas. El comercio oficial quedó interrumpido, y los gobiernos aliados y neutrales, advirtiendo el interés que para las industrias militares encerraba la química orgánica, se apresuraron a poner en marcha políticas de fomento de la industria nacional. Estas políticas, unidas a elevadas barreras proteccionistas, se mantuvieron después de la contienda, y resultaron, en casi todos los casos, 
eficaces. Para hacer frente a este entorno adverso, las empresas alemanas diseñaron estrategias nuevas: buscaron una asociación más fuerte que la de las convenciones, la Interessengemeinschaft Farbenindustrie AG (IG Farben, o IG a partir de ahora), constituida en 1925; dieron prioridad a la diversificación, con el fin de compensar la pérdida del monopolio de conocimientos y de posiciones de mercado en los sectores maduros; y llevaron a cabo inversiones directas en los países de mayor interés comercial, bien a partir de sus representaciones comerciales, o bien adquiriendo participaciones en empresas locales. Estas estrategias, más el nacionalismo industrial desplegado en casi todo el mundo, hicieron posible un florecimiento sin precedentes de empresas e instituciones de química aplicada, que explica a su vez la impresionante difusión tecnológica que tuvo lugar en el período de Entreguerras. La capacidad de consumo de los países más avanzados, no obstante, no experimentó grandes aumentos, por lo que la sobreproducción empezó a convertirse en un problema de primer orden. La respuesta fue la creación de carteles internacionales, en muchos casos bajo la égida de la IG Farben.

Bastante más estimulantes que los acuerdos internacionales resultaron, para la industria química moderna, el ascenso del nacionalsocialismo y la Segunda Guerra Mundial. Los países colaboracionistas u ocupados por Alemania, algunos de los cuales sólo habían mantenido hasta entonces posiciones periféricas en la química internacional, tuvieron la oportunidad de incorporarse al proceso de difusión tecnológica. Y las industrias de los países aliados atendieron la demanda militar más importante de la historia. La transferencia de conocimientos continuó durante la posguerra. En virtud de los acuerdos de Bretton Woods, las empresas alemanas fueron expropiadas en casi todos los países, y adquiridas por multinacionales aliadas o por industriales locales. También se procedió a desmantelar la IG, que concentraba a casi todas las firmas del sector (con la excepción notable de algunas farmacéuticas) y era la mayor del mundo. Las empresas fundadoras - Bayer, Hoechst y Badische Anilin- \& Soda-Fabrik (BASF), singularmente- recuperaron de este modo su identidad primitiva. Con todo, el problema más importante al que se enfrentarían las firmas alemanas en los años cincuenta y sesenta no fue la expropiación, que en muchos casos se compensó firmando contratos de licencia con los nuevos propietarios, sino la necesidad de adaptarse a la nueva fuente de alimentación de la industria química moderna: el petróleo. Como en el resto de los países europeos, en Alemania la petroquímica, erigida con la colaboración de empresas estadounidenses, se convirtió en el corazón de la industria 
química. Sobre esta base, las empresas alemanas tratarian, una vez más, de recuperar sus mercados tradicionales y conquistar algunos nuevos.

El mercado español, explorado precozmente por las casas de colorantes alemanas, fue secundario para la mayor parte de ellas hasta 1914, pero todas establecieron representaciones comerciales en el área de Barcelona. El auge que la Primera Guerra Mundial provocó en industrias españolas como la textil - la primera consumidora de colorantes-, sin embargo, alentó iniciativas locales y de los pocos competidores internacionales de los alemanes, los industriales suizos. Esta actividad se extendió a otros sectores que compartían primera materia y tecnología con los colorantes, como los explosivos o la farmaquímica. Desde 1917, los nuevos empresarios contaron además con el apoyo explícito que la Ley para la Protección de la Industria Nacional brindaba, y, después de la guerra, con elevados aranceles que protegian el mercado interior de la competencia extranjera. También aquí, pues, las firmas alemanas tuvieron que reorientar su estrategia de penetración del mercado español. Para cubrir la demanda de los productos más maduros se optó por la inversión directa, con o sin socios locales, y, para los más novedosos, se siguió empleando la espléndida red comercial existente. Sobre estas bases, y al calor de la colaboración franquista con el nacionalsocialismo, el negocio químico germano experimentaría un crecimiento explosivo en el curso de las guerras civil y mundial. El efecto conjunto del nacionalismo industrial de la dictadura y de los intereses bélicos de Alemania hizo que en España surgieran muchas plantas industriales y se multiplicaran los contratos de licencia, lo que creó oportunidades para muchos industriales españoles con más o menos experiencia en el sector. Estas oportunidades se ampliarían considerablemente después de que Alemania perdiera la guerra, ya que la Administración franquista se apresuró a hacer suyas las disposiciones aliadas y a expropiar y adjudicar mediante concurso los bienes alemanes. Desde 1950, los nuevos propietarios gestionaron las empresas en estrecho contacto con los alemanes, lo cual facilitaría el regreso oficial de éstos en el marco de apertura y liberalización de los sesenta. Ya en 1950, de hecho, España aparecía como el país con más inversiones químicas alemanas, y desde las centrales se consideraba el trampolín más importante para reconquistar el mercado europeo. El proceso de integración europea de España no ha hecho más que reforzar la posición de las multinacionales alemanas en el país, a pesar incluso de la incertidumbre que creó en 1990 la reunificación alemana.

Las numerosas ocasiones que la industria química española ha tenido de absorber conocimientos industriales y comerciales de las firmas ale- 
manas, contrastan con el pobre proceso de difusión e innovación tecnológicas registrado. ¿Por qué? Analizando el proceso de modernización de la industria química mundial, se comprueba que fue en el período de Entreguerras cuando las empresas de los países más innovadores imitaron a las alemanas y crearon sus propias capacidades de producción y comercialización. Por esta razón, en este trabajo exploramos, en perspectiva comparada, las estrategias de crecimiento de la industria química germana en España, así como las respuestas que los industriales locales y los gobiernos dieron a aquéllas antes de 1936. Nuestro objetivo es doble: examinar la política expansiva de la química alemana en España, y analizar, en un sector concreto y con fuentes primarias nuevas, el proceso de difusión tecnológica y de formación de capacidades sociales que acompañó a la incipiente industrialización española durante la segunda revolución industrial ${ }^{1}$. En la primera parte del artículo resumimos brevemente la historia de la industria química española en el contexto internacional. En la segunda pasamos a analizar la actividad exportadora de las empresas alemanas antes y después de la Gran Guerra. Y en la tercera reconstruimos el proceso de inversión directa que tuvo lugar durante el mismo período. Cierra el trabajo una serie de conclusiones con las que se pretende explicar por qué en España, y a pesar del nacionalismo industrial puesto en marcha en 1917, no se crearon las capacidades precisas para absorber los conocimientos que los alemanes brindaban a través de la exportación y la inversión directa, y crear una industria propia e innovadora.

\section{LA INDUSTRIA QUÍMICA ESPAÑOLA EN EL CONTEXTO INTERNACIONAL}

Entre 1880 y 1939, España desempeñó un papel marginal en la química mundial, cuyo centro ocupaba Alemania. El ascenso de este país desde mediados del xIX supuso el desplazamiento de Gran Bretaña y de Francia y el declive de la química pesada inorgánica a favor de la química orgánica. Sin duda, el sector que mejor representa este cambio es el de los colorantes, los pautadores de la química orgánica hasta bien entrado el siglo Xx. En la industria de los colorantes sintéticos, obtenidos a partir del alquitrán de hulla, cristalizaron los que tradicionalmente se han considerado factores

${ }^{1}$ Somos obviamente tributarios de las obras seminales de Pollard (1991), pp. 175-230, y Abramovitz (1986). Una propuesta para el caso español, en Comin (1997), pp. 6-10, $17-21$. 
explicativos del éxito industrial germano: naturales (abundancia de primeras materias y buenas comunicaciones); institucionales (excelentes equipos de investigación aplicada, disponibilidad de capital, ley de patentes adecuada, mano de obra preparada y fiscalidad ligera), y de gestión (interés de los empresarios por la investigación y la comercializàción, y acuerdos entre empresas) ${ }^{2}$. Los fabricantes de colorantes sintéticos fueron los primeros en aprovechar estas condiciones para crecer y modernizarse. Este proceso, que llegó a ser ejemplar en el ámbito del capitalismo industrial, se caracterizó por la aplicación sistemática de la innovación, la especialización, la integración vertical y el diseño de una eficaz política de ventas. En 1880 ya existían las ocho empresas más importantes de colorantes: Farbenfabriken vorm. Bayer \& Co. (Bayer), Badische Anilin- \& Soda-Fabrik AG (BASF), Hoechst Farbwerk AG (Hoechst), AG für Anilin-Fabrikation (AGFA), Leopold Cassella \& Co. (Cassella), Chemische Fabrik Griesheim-Elektron (Griesheim), Kalle \& Co. (Kalle) y Weiler-ter-Meer (Ter Meer) ${ }^{3}$. Estas firmas producían entre el 80 y el 90 por 100 de los colorantes sintéticos del mundo en 1900.

La fabricación de colorantes sintéticos se convirtió pronto en un buen negocio. Al principio, y para atraer capitales a un sector industrial todavía incierto, las compañías tuvieron que ofrecer dividendos muy superiores a lo habitual. Pero los beneficios no se hicieron esperar. En las fábricas de colorantes se empleaban como materias primas residuos de las industrias del gas y la siderurgia, como el alquitrán de hulla y sus derivados benceno, antraceno y naftaleno, que eran baratos. El incremento de la escala llevó a una caída de los precios impresionante ${ }^{4}$. En un adelanto de lo que sería la estrategia básica del sector, el primer colorante, la alizarina - de menor valor añadido y complejidad técnica- se fue abandonando a favor de los otros dos grandes grupos de colorantes, las anilinas y el añil. Dentro de éstos se buscó lo más complejo e innovador, especializándose cada firma en uno o varios productos. Desde el cambio de siglo, los colorantes permitieron financiar la importante labor investigadora y la consiguiente política de diversificación de las firmas hacia campos más prometedores, como los medicamentos, la síntesis del nitrógeno, o los productos fotográficos.

${ }^{2}$ Véanse los análisis magistrales de Haber (1958), pp. 128-136; (1971), pp. 120-134; Chandler (1990), pp. 474-481, y Arora et al. (1998), pp. 27-70.

${ }^{3}$ Todas cuentan con historias conmemorativas recientes. Véanse las de Bayer AG (1988), BASF (1990) y Hoechst AG (1990).

4 Entre 1880 y 1905 el precio de la alizarina cayó de 3,45 libras a 1,66; el de la anilina, de 14,76 a 2,74, y el del añil, de 11,66 a 2,29. Haber (1958), pp. 219-223. 
En 1908 eran ya las empresas más rentables del sector químico, y los colorantes sintéticos habían desplazado a los naturales casi completamente.

El éxito de los colorantes sintéticos atrajo a muchos industriales, y les permitió prescindir del respaldo de la banca. En un contexto de fuerte competencia, así, la búsqueda de acuerdos entre empresas se consolidaría como otra estrategia de crecimiento. El principal instigador del proceso fue Carl Duisberg, el nuevo presidente de Bayer, quien, impresionado por los avances de la industria americana en general, defendió desde 1904 una alianza nacional de la química orgánica. Se tuvo que conformar con un acuerdo parcial, la «pequeña» IG Farben, que desde 1906 agrupaba a Bayer, BASF y AGFA. Hoechst, por su parte, respondió estableciendo acuerdos con otras dos empresas menores, Cassella y Kalle, y fundando una segunda «pequeña» IG Farben ${ }^{5}$. En ambos casos se trató de acuerdos informales sobre precios y consultas periódicas sobre la marcha del negocio, que sustituyeron a las llamadas convenciones entre fabricantes del mismo colorante. Esta acción colectiva estuvo acompañada de la organización corporativa de los industriales del sector en la influyente asociación Verein zur Wabrung der Interessen der Chemischen Industrie, editora de la publicación especializada más importante, Die Chemische Industrie.

En los mercados exteriores, los acuerdos entre empresas fueron menos frecuentes. Los alemanes se mostraron muy pronto partidarios de la venta directa mediante representantes propios, lo que facilitaba el asesoramiento y la asistencia técnica a los clientes. La lucha entre representantes fue feroz. A esto se unió el creciente proteccionismo de los principales países compradores, que obligó a las compañías a bajar precios y a intensificar las estrategias de penetración. El incremento de la productividad en las plantas alemanas hizo posible lo primero. Lo segundo fue también viable gracias a la ampliación continua de la gama de productos y a los servicios de los representantes. Pero, al mismo tiempo, la mayor parte de las casas establecieron acuerdos con empresas locales para facilitar la penetración. El objetivo prioritario era garantizar la exportación, salvando las barreras del proteccionismo por la vía de las filiales o de los representantes. Los resultados de las políticas de expansión internacional de las firmas alemanas no tardaron en llegar y, en vísperas de la Gran Guerra, la industria química alemana era la primera del mundo ${ }^{6}$.

' Haber (1958), pp. 224-230; Chandler (1990), pp. 506-512 y 563.584; Plumpe (1990), pp. $40-63$.

6 Véanse el ejercicio cuantitativo de Goertz (1990). 
El estallido de la Primera Guerra Mundial pondría fin a tan floreciente negocio. El comercio oficial quedó virtualmente interrumpido entre los Estados centrales y la países de la Entente, creando un vacío que los países neutrales o alejados del escenario bélico se apresurarian a llenar. El que estaba en mejores condiciones de hacerlo era Suiza, que contaba ya con una industria avanzada y complementaria de la de sus vecinos del norte del Rin. Por su parte, los gobiernos aliados, que ya habían reconocido el interés potencial de esta industria para la guerra, adoptaron un intervencionismo insólito, que se plasmó en un apoyo directo e indirecto a las empresas locales y en un proteccionismo sistemático y selectivo. Los empresarios locales supieron aprovechar en casi todos los casos la coyuntura favorable. De ella se beneficiaron tanto países con tradición industrial (como Gran Bretaña y Francia, que se habían quedado atrás en la química orgánica, reducidos a meros suministradores de primeras materias o de colores básicos) como países nuevos en el sector (Japón, Italia y varios países nórdicos y centroeuropeos). Aunque el proceso fue especialmente llamativo en el caso de los colorantes, la proliferación de industrias y la dispersión, por tanto, de la química mundial se produjo en todos los subsectores modernos.

La posguerra daría así paso a un escenario muy diferente. La sobrecapacidad, unida a las barreras arancelarias, se tradujo en guerras comerciales, caída de precios y acuerdos de todo tipo entre firmas alemanas. En un clima de inseguridad, los carteles y fusiones proliferaron ${ }^{7}$. La actuación más importante fue la creación de la IG Farbenindustrie AG entre 1916 y $1925^{8}$. Las firmas alemanas comprendieron muy bien que el centro de gravedad de la química se estaba desplazando de los colorantes a otros campos más complejos aún y de mayor interés comercial, como los fármacos, el nitrógeno y los plásticos. Esto llevó a intensificar la investigación y el desarrollo, principales motores de la diversificación. Las empresas alemanas dieron muestras de gran habilidad para desplazar sistemáticamente la frontera de innovaciones y asegurarse el liderazgo tecnológico en los campos nuevos. Desde el punto de vista comercial, el interés de los alemanes siguió más centrado en los mercados exteriores que en el interior. Pero el clima político y económico de Entreguerras dificultó extraordinariamente la recuperación de los viejos clientes, por lo que se optó por formar alianzas con fabricantes locales en el exterior ${ }^{9}$. El surgimiento de

${ }^{7}$ Haber (1971), pp. 250-278.

' Haber (1971), pp. 352-375.

9 Schröter (1990), pp. 1-22; Jones \& Schröter (1993), pp. 28-48. 
poderosos competidores en los mercados tradicionales hizo que además se buscaran mercados nuevos para los productos clásicos, y que se tratara de mantener los antiguos para las nuevas gamas de productos. Como antes de la guerra, la misión de las exportaciones era mantener la escala de producción y financiar buena parte de las inversiones en investigación en Alemania.

En el período de Entreguerras, la acción combinada de las políticas industriales, las nuevas inversiones y el clima cada vez más competitivo, fue esencial para que en muchos países se creara un conjunto de capacidades científicas, industriales y comerciales, que es, junto a la estrategia de los pioneros alemanes, la que explica la difusión tecnológica, extraordinaria, de la industria química moderna ${ }^{10}$. Lejos de estancarse en la química del XIX, las empresas de los países más industrializados aprovecharon la oportunidad que se les brindaba para incorporar los procedimientos de fabricación de los subsectores más maduros y explorar campos nuevos. Desde finales de los años veinte, estas empresas y la IG y otras compañías alemanas estuvieron en condiciones de formar sindicatos con el fin de distribuirse los mercados mundiales, saturados, de colorantes y fertilizantes ${ }^{11}$.

España no estuvo presente en los carteles químicos. Y eso que la Primera Guerra Mundial creó grandes oportunidades para la industria hispana ${ }^{12}$. Su condición de neutral le permitió convertirse en suministrador de los beligerantes y atender la demanda creciente del mercado interior. Para las industrias tradicionales, como la de explosivos o ácido sulfúrico, la nueva situación no exigió grandes cambios. Desde finales de siglo habían ido surgiendo empresas importantes en estos sectores, con una participación sustancial de capital y tecnología extranjeros. Unión Española de Explosivos (UEE) (1896), Electro-Química de Flix (1897), Carburos Metálicos (1897), Unión Resinera Española (URE) (1898) y Cros (1904) constituían buenos ejemplos de la primera oleada fundacional de la industria química española ${ }^{13}$. A su lado crecía la filial de la multinacional belga Solvay (1904).

${ }^{10}$ Véanse, para el Reino Unido, Reader (1970), pp. 258-281 y 425.450; (1975) pp. 183-195 y 329.337. Para Estados Unidos, Hayes (1945), pp. 209.280; (1948) pp. 227-244. Para Japón, Kudo (1994), pp. 159-193. Para Italia, Amatori \& Bezza (1990) pp. 63-95, y Petri (1998), pp. 275-300. Un panorama internacional, en el famoso informe de Ungewitter (1927) para la Sociedad de Naciones.

${ }^{1}$ Ungewitter (1931), League of Nations (1947) y Schröter (1987), pp. 479.513.

12 Puig (1998), pp. 301-320.

${ }^{3}$ Véanse los trabajos de Tortella $(1983,1987$ y 1992) sobre la UEE. La Sociedad Electro-Química de Flix cuenta con dos historias conmemorativas (1966 y 1997). Sobre 
Los sectores nuevos, como los colorantes, fertilizantes, fármacos o fibras artificiales, estaban en cambio mal representados en España, por lo que la virtual interrupción del comercio exterior en 1914 obligó a realizar un gran esfuerzo técnico y financiero para introducirlos. Las iniciativas proliferaron, tal como revela el Anuario Financiero y de Sociedades Anónimas, que se empezó a publicar precisamente en 1917. Pero pocas sobrevivirían: Energía e Industrias Aragonesas (EIA) (1918), Instituto de Biología y Sueroterapia (1919), Fabricación Nacional de Colorantes y Explosivos (FNCE) (1922), Sociedad Ibérica del Nitrógeno (SIN) (1923), Sociedad Anónima de Fibras Artificiales (1923) o La Seda de Barcelona (1925) ${ }^{14}$. La veterana Cros, por su parte, supo hacerse un lugar preferente en el negocio de los superfosfatos, el capítulo más brillante de la química de Entreguerras en nuestro país, pero de poca complejidad tecnológica. Y la otra gran empresa del sector, UEE, puso en marcha un plan de diversificación que la llevó, fundamentalmente, a la minería.

En el contexto de la química internacional, sin embargo, antes y después de la Gran Guerra, la industria española no podía ser considerada sino como naciente. La comparación con los líderes europeos nos lleva a apuntar que las condiciones naturales eran claramente desfavorables, por más que en los medios españoles fuera habitual ponderar la riqueza mineral peninsular y considerarla la base de las grandes expectativas de la industria química nacional ${ }^{15}$. Fuera del país, por el contrario, se evaluaban las posibilidades españolas con gran escepticismo. Así, en 1920, Carl Duisberg afirmaba en una carta a uno de los directores del Deutsche Bank, Arthur Gwinner, que España no era un país adecuado para la química ${ }^{16}$. Aunque otros dictámenes, como el del Departamento de Comercio de los Estados Unidos, fueran más esperanzadores, es difícil negar que el déficit energético, las malas comunicaciones y el reducido mercado interior constituían

URE, Uriarte (1996). La de Cros sigue por hacer, a pesar de que Vicens y Vives anunciara en 1958 que se encontraba en curso de publicación el trabajo «La industria química y el potencial económico español a través de un Cincuentenario: Cros, S. A.» (1904-1954)», Vicens i Vives (1958), p. 63. Sus inicios pueden seguirse en Nadal (1986), pp. $42-44$ y (1993), pp. 149-155.

${ }_{14}$ EIA y SIN han sido analizadas por Bustelo (1957), pp. 23.40, y Nadal (1993), pp. 157-161, y FNCE, por Puig (1999).

${ }^{15}$ Como botón de muestra, véase el texto de la conferencia de Antonio M. Llopis, «La industria química en España» (12 de marzo de 1929), recogida en el Anuario de Industrias Quimicas (1932). Llopis fue uno de los empresarios más activos en el movimiento corporativo del sector durante todo el período.

16 BAL 84-30. 
serios obstáculos para el desarrollo de la química moderna ${ }^{17}$. La demanda industrial había frustrado ya en las últimas décadas del XIX el crecimiento de la química pesada. Pero durante las primeras del $\mathrm{xx}$, una creciente demanda agraria y de bienes de consumo -que partía de niveles muy bajos- alentaría la producción e importación de fertilizantes y fármacos.

Todavía más importante que la dotación natural o las limitaciones del mercado local sería el marco institucional. De hecho, la experiencia de la guerra había puesto de manifiesto que éste podía compensar con éxito aquéllas. Los suizos, que habían crecido a la sombra de los alemanes, eran un buen ejemplo de ello. Así lo entendían los industriales de dos países rezagados, Italia y Japón, que aprovecharon la guerra y la escalada militar posterior para crear una industria química nacional. En ambos casos se diseñaron sistemas de protección arancelaria y se recurrió a la intervención directa para animar a los empresarios. Los proyectos más o menos autárquicos del fascismo hicieron lo demás. Los especialistas coinciden en señalar que estos aranceles, tardíos y selectivos, fueron eficaces, pero que otros factores tuvieron bastante más influencia en el crecimiento de la química ${ }^{18}$. El gobierno italiano forzó muchas decisiones de la primera empresa del país, Montecatini, de la que era además un cliente importante. En 1916 se crearon dos comités sectoriales, uno industrial y otro científico-técnico, que en las décadas posteriores contribuyeron a consolidar políticas e instituciones de fomento de la industria química. En Japón, el Estado participó en una de las grandes empresas químicas, Nihon Senryo - nacida durante la guerra-, y fue un interlocutor permanente de los grupos más interesados por la química, Mitsui y Mitsubishi. Los empresarios tuvieron igualmente su importancia a la hora de modelar y hacer eficaz el entramado institucional. Sin la figura de Donegani, por ejemplo, Montecatini podría haber seguido una trayectoria bastante más mediocre, y quizás Fauser hubiera tenido que buscar - como Marconi-- socios capitalistas fuera de Italia. Este contexto influiría notablemente en la estrategia de las filiales alemanas en Japón e Italia. Varios países escandinavos aprovecharon su neutralidad para poner las bases de la industria química. Y hubo experiencias brillantes, apoyadas por recursos naturales abundantes, infraestructura científica y técnica y disponibilidad de capitales ${ }^{19}$. Los países centroeuropeos, en cambio, hicieron de la política industrial y arancelaria el principal instrumento para

17 U.S. Department of Commerce (1933), pp. 49-52.

18 Zamagni (1990), pp. 69-148, Petri (1998), pp. 275-300, y Kudo (1994), pp. 159-183.

${ }_{14}$ Véanse los análisis de Suecia, Noruega, Dinamarca y Finlandia en Travis et al. (1998), pp. 123-141, 239-271, 321-339 y 341-360. 
librarse de la dependencia de la vecina Alemania y crear industrias químicas nacionales. Los resultados fueron bastante más modestos, y las empresas extranjeras disfrutaron, en general, de un amplio margen de maniobra ${ }^{20}$. Portugal, por último, apenas participó del nacionalismo químico de la época. Continuó exportando productos naturales e importando - casi siempre a través de España - productos manufacturados ${ }^{21}$.

Pero en España no se dieron, ni antes ni después de la guerra, transformaciones importantes en este sentido. Nominalmente, los gobiernos españoles habían apostado por la industria química, en el marco de la industrialización general, desde finales del siglo pasado. Y lo había hecho por la vía decimonónica por antonomasia, la protección del mercado interior (aranceles de 1892, 1906 y 1921, fundamentalmente), así como por la más novedosa senda del proteccionismo industrial (representado por las leyes de 1917 y 1924). Muchos de los sectores más visibles de la química fueron considerados «de interés nacional», y pasaron a gozar de una serie de privilegios arancelarios y fiscales ${ }^{22}$. Pero la eficacia de la legislación quedaba condicionada por la actividad de los organismos encargados de aplicarla, como la Comisión Protectora de la Producción Nacional o el Consejo de Economia Nacional, y por las continuas negociaciones arancelarias, lo que hace necesario un análisis casuístico exhaustivo para determinar si fue efectivo o no ${ }^{23}$. El caso de los colorantes sintéticos, por ejemplo, sugiere que la maquinaria administrativa funcionó poco y mal, y que no hubo una estrategia arancelaria consecuente. Esto provocó que las empresas tuvieran que dedicar grandes energías a las relaciones con la Administración, por una parte, y que su marco de actuación fuera siempre incierto. Las otras grandes partidas que vamos a examinar, por el contrario, presentaron niveles de protección muy bajos, a pesar de que, en algunos informes internacionales, España apareciera como el país que más protegia su química, después de Rusia y Polonia ${ }^{24}$.

21) Véanse los breves informes nacionales sobre Polonia, Austria y Hungría en: U.S. Department of Commerce (1933), pp. 52-62. El informe sobre la industria química encargado por la Sociedad de Naciones al experto alemán Ungewitter dedica bastante atención a estos países. Los datos sobre aranceles fueron contestados enérgicamente por el presidente de la patronal polaca, en lo que constituye un testimonio excepcional del nacionalismo económico de Entreguerras: Ungewitter (1927), pp. 127.137.

${ }^{21}$ U.S. Department of Commerce (1933), pp. 68-70.

22 Un ejemplo del discurso oficial se encuentra en el opúsculo de Suárez Inclán (1922).

${ }^{23}$ Comisión Nacional de la Productividad Industrial $(1918,1924)$, Consejo de Economía Nacional $(1924,1925$ y 1927), Anuario Aduanero de España (1931 y 1934).

${ }^{24}$ Ungewitter (1927), pp. 36-40, 54-60. 
El otro pilar de moderna química industrial, la investigación aplicada, no recibió en España apoyos públicos dignos de mención. Las universidades seguían orientadas al conocimiento teórico y pobremente dotadas de medios humanos y materiales. La química industrial ocupaba un lugar secundario en los programas y en los edificios de las escuelas de ingeniería industrial, y la ingeniería química aún no se había introducido. Hubo, no obstante, dos iniciativas muy modestas, pero significativas, en la química industrial: el Instituto Químico de Sarrià, creado por la Compañía de Jesús en 1916, y el Institut de Química Aplicada de la Mancomunitat de Catalunya, del mismo año ${ }^{25}$. Si el primero ha sobrevivido hasta hoy, desempeñando un papel notable en el desarrollo de la química catalana, el segundo fue víctima del iracundo antirregionalismo del general Primo de Rivera, que lo cerró en 1925. En ambos casos se trataba de instituciones minúsculas, pero al corriente de las innovaciones del exterior y con una clara vocación industrial. En ambos casos, también, había una personalidad impulsora del proyecto: Eduardo Vitoria en el primero y Josep Agell en el segundo. Las publicaciones periódicas de los dos - Afinidad y Química e Industria - indican que, conscientes de sus limitaciones, se contentaban con adaptar las innovaciones de los líderes a la industria española. La revista del instituto de Agell siguió publicándose hasta 1937 bajo los auspicios de la Cámara Nacional de Industrias Químicas, el principal foro de los industriales del sector, que en la segunda mitad de los veinte extendió su radio de acción desde Cataluña al resto de España. La investigación química de más alto nivel sólo podía, pues, hacerse en el seno de las industrias, y lo que sabemos de éstas es que carecían de departamentos de investigación. En el mejor de los casos contaban con laboratorios que servían para probar procesos y productos del exterior, o buscaban el asesoramiento de los institutos. La debilidad de este importantísimo factor de crecimiento de la industria química moderna en España apenas resiste comparaciones con otros países industriales o en vías de industrialización. Las trayectorias nacionales o empresariales más luminosas estuvieron siempre vinculadas a individuos o departamentos innovadores. Noruega y Japón proporcionan algunos ejemplos, pero el más revelador es sin duda el de Italia. La feliz - y excepcional - asociación entre Donegani y Fauser desde

${ }^{25}$ Puig Raposo y López García (1992 y 1994), Galí (1981), pp. 129-134. La actividad investigadora y difusora de las cátedras de Química Industrial de las Facultades de Ciencias Químicas y de las Escuelas Técnicas Superiores está por hacer. De momento, la pobreza de las publicaciones y la ausencia de académicos en la industria indican que fue insignificante, tal como se señalaba insistentemente en Química e Industria. 
1921 fue crucial para que Montecatini se convirtiera en una de las grandes empresas europeas de la época. Las innovaciones de Fauser en un solo campo, la fijación del nitrógeno, permitió que Italia estuviera presente en los carteles internacionales y amplió su margen de negociación con la IG y otros grupos dominantes. No es casual que Fauser estudiara en el Politécnico de Milán, y tampoco que fuera hijo de un industrial suizo.

Las monografías de grandes empresas químicas aparecidas hasta la fecha tampoco invitan a ser optimistas en el análisis de la gestión empresarial, otro factor explicativo del crecimiento de la química moderna. Casi todas ellas fueron conscientes de sus desventajas: carecían de muchos de los recursos naturales adecuados; llegaban tarde a sectores tecnológicamente maduros; y disponían de un mercado pequeño y muy dependiente de una agricultura pobre. Este hecho explicaría que muchas de las energías empresariales se concentraran en alcanzar posiciones de dominio en el mercado nacional, más que en desarrollar capacidades en los campos vitales de la investigación y la comercialización. La dependencia de las grandes firmas extranjeras se aceptaba —aparentemente- como algo inevitable, pero que podía negociarse en los términos más ventajosos. Esto ayuda a entender que en la organización interna, otro aspecto fundamental de la modernización industrial del primer tercio de siglo, tampoco se registraran grandes avances, consolidándose, en todo caso, cierta división del trabajo entre las direcciones «técnica» y «política» ${ }^{26}$. Para la moderna y pujante química orgánica alemana, España constituía, pues, un terreno prácticamente virgen.

\section{LAS EXPORTACIONES ALEMANAS DE PRODUCTOS QUÍMICOS}

La estrategia más clara de crecimiento de la moderna química alemana se manifestó en las exportaciones. Desde Alemania, España aparecía como un mercado fácil de abordar, pero de interés limitado. Si lo primero se debía, sobre todo, a la ausencia de competencia local, lo segundo era consecuencia del carácter persistentemente agrario, y pobre, de la población española. En el primer tercio de este siglo, al aumentar sensiblemente los niveles de industrialización y renta, empezó a prestarse más atención a España, pero aun así no llegó a ser un cliente importante de la química alemana, quedando siempre por debajo del 2 por 100 de las exportaciones

${ }^{26}$ Un rasgo característico de los países periféricos, como Italia. Petri (1998), pp. 280-284. El caso de FNCE, estudiado por Puig (1999), se adapta a este modelo. 
totales de los fabricantes germanos. Que éstos no tuvieron grandes inconvenientes para penetrar el mercado español lo muestran las estadísticas de comercio exterior, que pasamos a analizar.

La reconstrucción de las exportaciones alemanas a España presenta los problemas habituales de los ejercicios de este tipo, más las dificultades que se derivan de la complejidad de la industria química. El problema no estriba tanto en la falta de información como en la calidad, claridad y homogeneidad de la misma. Durante el largo período objeto de este estudio, los cambios en las denominaciones de los productos y los reagrupamientos de los mismos fueron muy frecuentes, y los verdaderos orígenes y destinos de los artículos estaban a menudo velados en los dos casos por el comercio de tránsito y la existencia de puertos francos. La estadística alemana, por último, experimentó un colapso durante la guerra y la turbulenta posguerra mundial, lo cual crea un vacío estadístico de diez años que no se produjo en la neutral España. Todas estas razones nos han impulsado a emplear ambas estadísticas, aunque en los cuadros sólo incluimos la Statistik des Deutschen Reiches (SDR) para el primer período (1880-1913) y la Estadística de Comercio Exterior de España (ECE) para el segundo período de nuestro estudio (1913-1935).

En el Cuadro 1 se recogen los datos de las estadísticas alemanas sobre las exportaciones de mayor peso en el sector químico entre 1880 y 1913. En esta primera etapa, los intereses de la química alemana estaban representados por los colorantes sintéticos. Las anilinas, primero, y el añil algo más tarde, lograron un gran poder de mercado en España. La principal razón de la hegemonía germana en España era la caída drástica de los precios. Mientras las exportaciones de anilinas se multiplicaban por treinta y cinco, y su precio se reducía a una quinta parte, las de añil, desde 1890 , se decuplicaban, experimentando una reducción de precios algo más modesta, pero significativa. La caída imparable de las alizarinas era el efecto de la sustitución de las mismas por las más novedosas anilinas. Los colorantes sintéticos alemanes no encontraron resistencia en el mercado espanol. Sus principales clientes eran los fabricantes textiles, que experimentaron una etapa de crecimiento entre 1880 y 1913 y se dejaron seducir pronto por las ventajas de las anilinas ${ }^{27}$. La competencia era raquítica, excepto en el terreno de los negros sulfurosos. Puede, pues, concluirse que también en España los colorantes fueron los pautadores de la industria

${ }^{27}$ Las importaciones de algodón se duplicaron en ese período. Carreras (1989), pp. 229-230. 


\section{CUADRO 1}

Exportaciones de Alemania a España, 1880-1913 (en Qm)

\begin{tabular}{|c|c|c|c|c|c|c|c|}
\hline \multirow{2}{*}{$A \bar{n} o s$} & \multicolumn{3}{|c|}{ Colorantes } & \multicolumn{2}{|c|}{ Fertilizantes } & \multicolumn{2}{|c|}{$\begin{array}{c}\text { Praductos } \\
\text { farmacéuticos }\end{array}$} \\
\hline & Anilina & Añil & Alizarina & Potásicos & $\begin{array}{c}\text { Sulfato } \\
\text { amónico }\end{array}$ & Preparados & $\begin{array}{c}\text { Sin } \\
\text { preparar }\end{array}$ \\
\hline $1880 \ldots \ldots \ldots$ & 185 & & 710 & & & & \\
\hline $1881 \ldots \ldots \ldots$ & 271 & & 664 & & & & \\
\hline $1882 \ldots \ldots \ldots$ & 340 & & 736 & & & & \\
\hline $1883 \ldots \ldots \ldots$ & 419 & & 895 & & & & \\
\hline $1884 \ldots \ldots \ldots$ & 560 & & 1.129 & & & & \\
\hline $1885 \ldots \ldots \ldots$ & 438 & & 498 & & & & \\
\hline $1886 \ldots \ldots \ldots$ & 433 & & 525 & & & & \\
\hline $1887 \ldots \ldots \ldots$ & 503 & & 449 & & & & \\
\hline $1888 \ldots \ldots \ldots$ & 587 & & 858 & & & & \\
\hline $1889 \ldots \ldots \ldots$ & 1.189 & & 875 & & & & \\
\hline $1890 \ldots \ldots \ldots$ & 1.017 & 65 & 715 & & & & \\
\hline $1891 \ldots \ldots \ldots$ & 1.156 & 55 & 803 & 2.886 & & & \\
\hline $1892 \ldots \ldots \ldots$ & 1.702 & 8 & 1.036 & 3.104 & & & \\
\hline $1893 \ldots \ldots . . .$. & 1.088 & 31 & 351 & 3.209 & & & \\
\hline $1894 \ldots \ldots \ldots$ & 1.655 & 64 & 1.066 & 3.254 & & & \\
\hline $1895 \ldots \ldots \ldots$ & 764 & 37 & 338 & 3.609 & & & \\
\hline $1896 \ldots \ldots \ldots$ & 954 & 8 & 304 & 4.941 & & & \\
\hline $1897 \ldots \ldots . .$. & 869 & 16 & 380 & 7.529 & & & \\
\hline $1898 \ldots \ldots \ldots$ & 1.381 & 61 & 377 & 8.507 & & & \\
\hline $1899 \ldots \ldots . . .$. & 2.373 & 137 & 186 & 22.553 & & & \\
\hline $1900 \ldots \ldots . . .$. & 3.098 & 214 & 563 & 20.907 & & & \\
\hline $1901 \ldots \ldots . .$. & 3.081 & 379 & 336 & 24.828 & & & \\
\hline $1902 \ldots \ldots \ldots$ & 4.078 & 577 & 434 & 16.536 & & & \\
\hline $1903 \ldots \ldots \ldots$ & 4.321 & 695 & 248 & 36.736 & & & \\
\hline $1904 \ldots \ldots \ldots$ & 4.639 & 718 & 202 & 39.507 & & & \\
\hline $1905 \ldots \ldots \ldots$ & 4.787 & 633 & 227 & 45.697 & & & \\
\hline $1906 \ldots \ldots . .$. & 5.998 & 885 & 158 & 56.238 & & & \\
\hline $1907 \ldots \ldots . . .$. & 3.798 & 831 & 139 & 58.150 & & & \\
\hline $1908 \ldots \ldots \ldots$ & 4.504 & 783 & 127 & 85.046 & 24.410 & 98 & 108 \\
\hline $1909 \ldots \ldots \ldots$ & 4.964 & 929 & 132 & 96.672 & 5.310 & 79 & 112 \\
\hline $1910 \ldots \ldots \ldots$ & 4.938 & 640 & 36 & 120.435 & 87.730 & 104 & 136 \\
\hline $1911 \ldots \ldots \ldots$ & 6.295 & 691 & 56 & 175.634 & 40.660 & 117 & 276 \\
\hline $1912 \ldots \ldots \ldots$ & 7.341 & 736 & 122 & 123.320 & & 182 & 165 \\
\hline $1913 \ldots \ldots \ldots$ & 6.555 & 670 & 91 & 209.692 & 25.500 & 313 & 313 \\
\hline
\end{tabular}

Fuente: Statistik des Deutschen Reiches. 
química alemana. En 1913, los alemanes suministraban cerca del 85 por 100 de las anilinas y casi el 93 por 100 del añil importados.

Del segundo pilar de las exportaciones germanas, los fertilizantes, sólo destacan, antes de 1913, los potásicos, que hicieron acto de aparición en la década de 1890 y experimentaron un ascenso meteórico hasta la guerra. Creemos, sin embargo, que este producto no es representativo de la química industrial alemana, pues sus exportadoras eran empresas de carácter más minero que industrial y aprovechaban la excelente dotación natural del país. Sólo mucho más tarde, en pleno proceso de concentración y diversificación de entreguerras, se establecerían relaciones entre las industrias más innovadoras (como la IG Farben) y los fertilizantes potásicos. Bastante más interés desde el punto de vista industrial reviste el sulfato amónico, que empezó a exportarse a España en 1908. A diferencia de lo que ocurría con los colorantes, los alemanes contaban aquí con competidores notables, británicos y holandeses sobre todo. Dado que las estadísticas españolas agregan todos los abonos «minerales», no nos es posible saber cuál era la cuota de mercado de cada uno de ellos antes de 1922.

Los productos farmacéuticos constituían la tercera partida importante de las exportaciones químicas germanas. Aunque se convertiría en un sector prometedor, sus inicios fueron modestos. Los suministradores tradicionales del mercado español, Francia, Gran Bretaña y cada vez más Estados Unidos, siguieron dominando el mercado hasta la Gran Guerra con alcaloides, sueros y vacunas. Alemania, en cambio, se especializaría en los «productos farmacéuticos sin preparar», esto es, sustancias sintéticas como los ácidos salićlico o acetilsalićlico con los que desde 1897 se elaboraría la famosa aspirina. En 1913, Alemania se limitaba a proporcionar cerca del 20 por 100 de los «preparados».

La progresiva conquista del mercado español por parte de la industria química alemana se truncó con la Primera Guerra Mundial. Ésta abrió una etapa claramente distinta en las estrategias de crecimiento y en la evolución del sector. La exportación, que siguió siendo un objetivo prioritario, cedió ante las nuevas circunstancias: la propia guerra; las dificultades de la posguerra y los efectos devastadores de la hiperinflación; y el férreo proteccionismo que se instaló en Europa, como parte integral del interés público por los sectores considerados estratégicos. Este nuevo marco impulsó la concentración y la búsqueda de acuerdos entre empresas dentro y fuera de Alemania. España no constituyó una excepción. Al contrario, la guerra alentó una política intervencionista que afectaba directamente a la industria química. En los Cuadros 2, 3 y 4 puede seguirse la evolución 
CUADRO 2

Importaciones de colorantes sintéticos, 1913-1935 (en Qm)

\begin{tabular}{|c|c|c|c|c|c|c|}
\hline \multirow{2}{*}{ Años } & \multicolumn{3}{|c|}{ Colorantes de anilina } & \multicolumn{3}{|c|}{ Añil } \\
\hline & Total & Alemania & Porcentaje & Total & Alemania & Porcentaje \\
\hline $1913 \ldots \ldots \ldots \ldots \ldots$ & 6.117 & 5.186 & 84,8 & 760 & 704 & 92,70 \\
\hline $1914 \ldots \ldots \ldots \ldots .$. & 10.448 & 5.160 & 49,4 & 706 & 517 & 73,18 \\
\hline $1915 \ldots$ & 2.544 & 1.747 & 68,7 & 1.855 & 1.244 & 67,07 \\
\hline $1916 \ldots \ldots$ & 2.359 & 944 & 40,0 & 2.202 & 1.434 & 65,11 \\
\hline $1917 \ldots$ & 3.718 & 562 & 15,1 & 2.443 & 69 & 2,82 \\
\hline $1918 \ldots \ldots \ldots \ldots \ldots . . . . . .$. & 4.420 & 60 & 1,4 & 4.170 & & \\
\hline $1919 \ldots \ldots \ldots \ldots \ldots$ & 8.548 & 229 & 2,7 & 1.335 & 50 & 3,75 \\
\hline $1920 \ldots \ldots \ldots \ldots \ldots \ldots$ & 14.416 & 4.724 & 32,8 & 1.782 & 958 & 53,71 \\
\hline $1921 \ldots \ldots \ldots \ldots \ldots$ & 7.985 & 5.542 & 69,4 & 889 & 401 & 45,18 \\
\hline $1922 \ldots \ldots \ldots \ldots \ldots$ & 8.148 & 6.615 & 81,2 & 1.475 & 1.275 & 86,47 \\
\hline $1923 \ldots \ldots \ldots \ldots \ldots$ & 6.053 & 4.100 & 67,7 & 498 & 236 & 47,38 \\
\hline 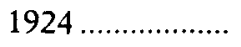 & 3.700 & 2.447 & 66,1 & 439 & 199 & 45,44 \\
\hline $1925 \ldots \ldots \ldots \ldots \ldots$ & 4.608 & 2.809 & 61,0 & 407 & 237 & 58,37 \\
\hline $1926 \ldots \ldots \ldots \ldots \ldots$ & 3.251 & 1.808 & 55,6 & 811 & 677 & 83,51 \\
\hline $1927 \ldots \ldots \ldots \ldots \ldots$ & 3.792 & 2.583 & 68,1 & 705 & 521 & 74,03 \\
\hline $1928 \ldots \ldots \ldots \ldots \ldots$ & 4.136 & 2.306 & 55,8 & 573 & 242 & 42,25 \\
\hline $1929 \ldots \ldots \ldots \ldots \ldots$ & 2.109 & 835 & 39,6 & 409 & 135 & 33,06 \\
\hline $1930 \ldots \ldots \ldots \ldots \ldots$ & 8.742 & 3.817 & 43,7 & 1.153 & 846 & 73,39 \\
\hline 1931 ...................... & 2.502 & 986 & 39,4 & 250 & 180 & 72,08 \\
\hline $1932 \ldots \ldots \ldots \ldots \ldots$ & 1.870 & 741 & 39,6 & 573 & 166 & 28,98 \\
\hline $1933 \ldots \ldots \ldots \ldots \ldots$ & 2.498 & 1.258 & 50,4 & 321 & 146 & 45,72 \\
\hline $1934 \ldots \ldots \ldots \ldots \ldots . . . . . . .$. & 3.372 & 1.583 & 46,9 & 376 & 208 & 55,27 \\
\hline $1935 \ldots \ldots \ldots \ldots \ldots$ & 4.221 & 1.796 & 42,5 & 407 & 235 & 57,80 \\
\hline
\end{tabular}

FUENTE: Estadística del Comercio Exterior de España

de las importaciones oficiales de los tres grandes grupos de productos químicos. Las de colorantes reflejan el proceso de sustitución de importaciones que, con bastante más lentitud que en el resto de los países europeos, se puso en marcha en España. El vacío oficial creado por la guerra fue ocupado rápidamente por los exportadores suizos y por las iniciativas locales. Pero los fabricantes alemanes volvieron a tomar posiciones en 1922, de modo que en ese año ya volvían a suministrar más del 80 por 100 de las anilinas. La evolución a partir de entonces presenta altibajos importantes, atribuibles a los de la agricultura y la producción textil, pero las importaciones tienden a caer. Con el añil ocurre algo parecido: registra 


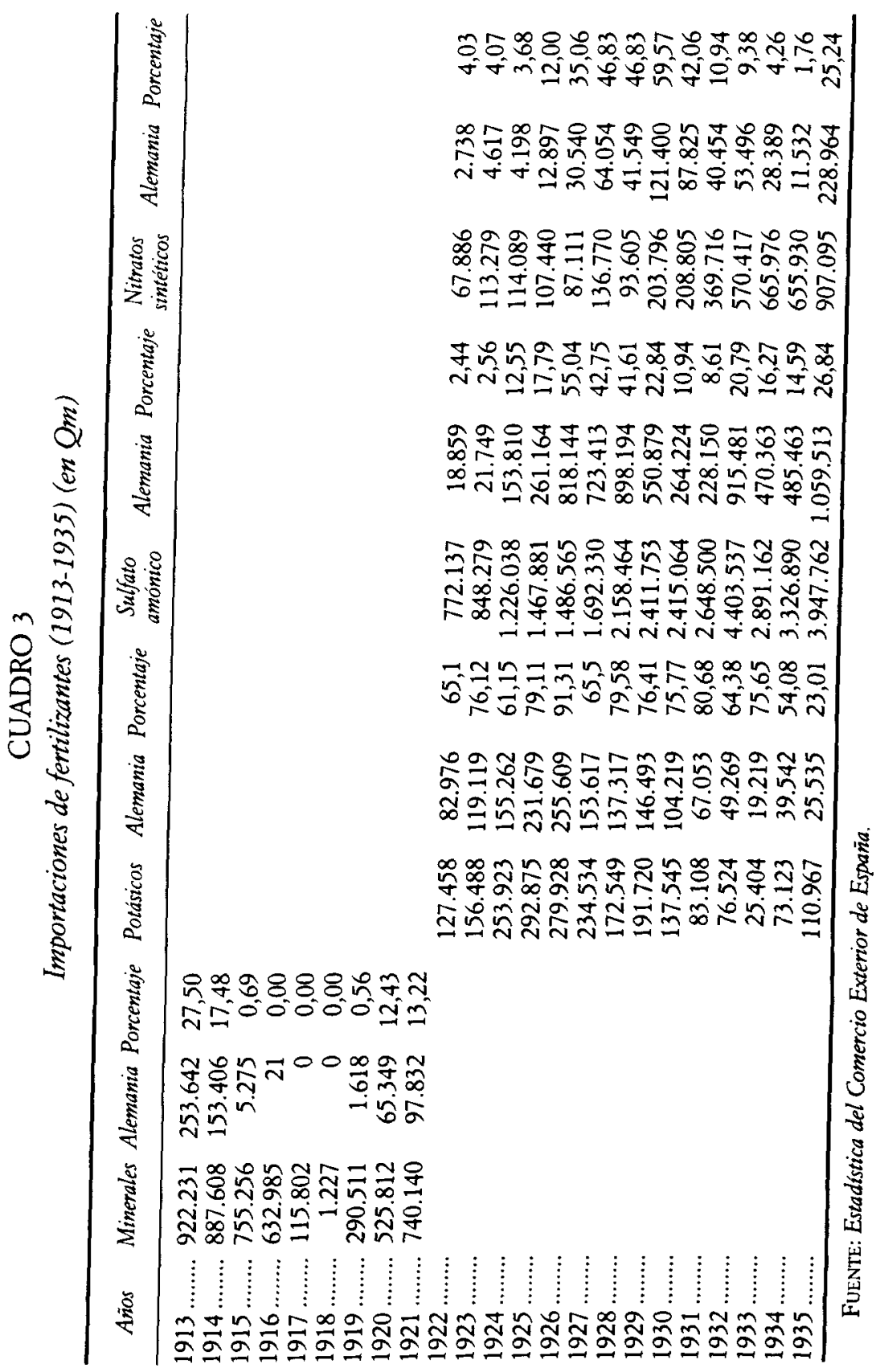




\section{CUADRO 4}

Importaciones de productos farmacéuticos, 1913-1935 (en Qm)

\begin{tabular}{|c|c|c|c|c|c|c|}
\hline$A \bar{n} o s$ & Preparados * & Alemania & Porcentaje & Sin preparar & Alemania & Porcentaje \\
\hline 1913. & 3.397 & 667 & 19,63 & & & \\
\hline $1914 \ldots$ & 2.801 & 509 & 18,17 & & & \\
\hline $1915 \ldots \ldots \ldots \ldots \ldots . . . . . . . .$. & 3.097 & 406 & 13,11 & & & \\
\hline $1916 \ldots \ldots \ldots \ldots$ & 3.293 & 23 & 0,7 & & & \\
\hline $1917 \ldots .$. & 4.242 & 18 & 0,42 & & & \\
\hline $1918 \ldots \ldots .$. & 3.848 & 71 & 1,84 & & & \\
\hline 1919 & 5.384 & 125 & 2,32 & & & \\
\hline $1920 \ldots \ldots \ldots \ldots \ldots$ & 8.440 & 791 & 9,37 & & & \\
\hline $1921 \ldots \ldots \ldots \ldots$ & 4.108 & 704 & 17,14 & & & \\
\hline $1922 \ldots \ldots \ldots \ldots \ldots$ & 2.042 & 233 & 11,41 & 223 & 140 & 62,78 \\
\hline $1923 \ldots \ldots \ldots \ldots$ & 1.680 & 245 & 14,58 & 216 & 148 & 68,51 \\
\hline $1924 \ldots \ldots \ldots \ldots \ldots \ldots$ & 2.251 & 261 & 11,59 & 408 & 299 & 73,28 \\
\hline 1925 & 2.524 & 290 & 11,49 & 390 & 309 & 79,23 \\
\hline $1926 \ldots \ldots \ldots \ldots \ldots . . . . . . . . . .$. & 2.727 & 350 & 12,85 & 437 & 332 & 75,97 \\
\hline $1927 \ldots \ldots \ldots \ldots \ldots$ & 2.736 & 411 & 15,02 & 200 & 156 & 78,00 \\
\hline $1928 \ldots \ldots \ldots \ldots \ldots \ldots$ & 3.246 & 486 & 14,97 & 285 & 237 & 83,16 \\
\hline $1929 \ldots \ldots \ldots . . . .$. & 3.353 & 625 & 18,64 & 295 & 279 & 94,58 \\
\hline $1930 \ldots \ldots \ldots \ldots \ldots$ & 3.625 & 784 & 21,63 & 297 & 279 & 93,94 \\
\hline $1931 \ldots \ldots \ldots . . . . .$. & 3.320 & 765 & 23,04 & 364 & 305 & 83,79 \\
\hline $1932 \ldots \ldots \ldots \ldots \ldots$ & 2.580 & 493 & 19,11 & 426 & 390 & 91,55 \\
\hline $1933 \ldots \ldots \ldots \ldots \ldots$ & 2.622 & 669 & 25,51 & 466 & 407 & 87,34 \\
\hline $1934 \ldots \ldots \ldots \ldots \ldots . . .$. & 2.734 & 1.018 & 37,23 & 541 & 399 & 73,75 \\
\hline 1935 & 2.989 & 1.157 & 38,71 & 720 & 501 & 69,58 \\
\hline
\end{tabular}

* Preparados: píldoras, medicamentos sin alcohol y demás medicamentos (que desde 1921 aparecen como especialidades).

una recuperación rápida hasta 1923, y cae desde ese año. De gran interés para interpretar esto son los datos sobre importación de materias intermedias, estratégicas para desarrollar una industria nacional o mantener vivo el flujo de mercancías entre Alemania y España. Hasta 1921 sólo contamos con datos sobre importación de aceite de anilina. Alemania suministró hasta 1913 un 60 por 100 de esta primera materia para la elaboración de colorantes sintéticos. Las importaciones se recuperarian en 1921. Desde ese año tenemos información más precisa sobre los intermedios más importantes, los derivados nitrados y clorados y la paranitranilina. La participación de Alemania en las importaciones de estas dos partidas aumentó del 9,53 por 100 y 28,40 por 100 en 1926 al 62,59 por 100 y al 54,86 por 100 
en 1930. Esto indica que el proceso de sustitución de importaciones de colorantes en España -liderado por empresas españolas o alemanasse hizo con el apoyo de Alemania.

La guerra también interrumpió las importaciones de abonos potásicos y sulfato amónico. La recuperación llegó a principios de los años veinte: los potásicos recuperaron y ganaron posiciones (absolutas y relativas), y el sulfato amónico experimentó un incremento importante, aunque sometido a oscilaciones. Éstas podían deberse a las pugnas en el seno del cartel internacional, o a la crisis económica española. Las importaciones totales se incrementaron progresivamente, y durante todo el período de Entreguerras los fertilizantes nitrogenados fueron los grandes ausentes en la producción industrial española, que apenas cubría un 2 por 100 del consumo español ${ }^{28}$. Alemania mantuvo entre un 10 por 100 y un 50 por 100 de cuota. Para analizar las estrategias de la industria química creemos, de nuevo, que los nitratos sintéticos revisten más interés. Ésta era una línea de producción importante para la IG Farben ${ }^{29}$. Entre 1922 y 1935, las importaciones españolas se multiplicaron por más de diez, y las procedentes de Alemania experimentaron incrementos muy notables, hasta alcanzar casi un 60 por 100 de cuota en 1929.

Los preparados farmacéuticos, uno de los productos más representativos de las mejoras en el nivel de vida de la emergente clase media europea de Entreguerras, fueron los grandes protagonistas de esta segunda etapa. El mercado español se convirtió en uno de los más importantes para los fabricantes alemanes. Las estadísticas muestran una recuperación vigorosa del bache de la guerra desde 1921, alcanzándose casi el 40 por 100 de todas las importaciones de preparados y lográndose una situación de casi monopolio (entre el 70 y el 95 por 100 de todas las importaciones) en el terreno de los no preparados. El producto estrella fue el ácido salićlico, cuyo precio se redujo a la mitad entre 1924 y 1935 en el mercado de Barcelona ${ }^{30}$. De nuevo, esta evolución muy favorable a los intereses germanos refleja el éxito de las inversiones directas de la industria farmacéutica alemana en España. Ésta, como se verá, salvó las restricciones de la legislación industrial española a las inversiones extranjeras transformando sus agencias de ventas en centros de confección y envasado de fármacos que trabajaban con productos importados de las centrales alemanas.

${ }^{2 \times}$ Carreras (1989), p. 226.

${ }^{24}$ Plumpe (1990), pp. 203-243.

${ }^{30}$ De acuerdo con las estadísticas mensuales de Quimica e Industria. 
Las exportaciones de la química alemana a España pasaron, en conclusión, por dos etapas diferentes entre 1880 y 1935. Hasta 1913, los colorantes sintéticos fueron un poderoso instrumento de penetración en el mercado interior, donde no existía apenas competencia ni de los fabricantes locales ni de los proveedores químicos tradicionales, Gran Bretaña y Francia. También se registraron avances significativos donde aquéllos estaban mejor implantados: fertilizantes potásicos, sulfato amónico y medicamentos. Tras el colapso de la guerra, y hasta 1935, tuvo lugar una recuperación importante de los colorantes. La recuperación se frustró a mediados de los veinte, en mayor medida para las anilinas - una industria ya maduraque para el añil, donde los alemanes seguían gozando de ventajas de fabricación. En los terrenos más dinámicos de los fertilizantes y fármacos, los avances fueron más importantes aún, conquistándose el mercado para el sulfato amónico y los abonos sintéticos, e incrementándose las ventas de especialidades farmacéuticas. Las barreras arancelarias tuvieron un efecto necesariamente limitado. Con la excepción de los colorantes, los productos fundamentales del comercio germano, las especialidades farmacéuticas, los fertilizantes nitrogenados $y$, sobre todo, los productos intermedios para la fabricación de colorantes y fármacos, estuvieron a lo largo del período poco gravados ${ }^{31}$. Aunque las negociaciones crearon con frecuencia incertidumbre entre exportadores e importadores, Alemania gozó del trato de la nación más favorecida. El hecho de que la industria química orgánica española estuviera penetrada por las firmas alemanas, resta valor a los precios como indicadores de la mayor o menor eficacia de la política comercial. Los precios oficiales de importación, los del mercado de Barcelona y los registrados en la contabilidad de las filiales alemanas, presentaban grandes disparidades. Los de las primeras materias desempeñaban, de hecho, un papel instrumental para las filiales.

\section{LAS INVERSIONES ALEMANAS EN ESPAÑA}

La trayectoria seguida por las importaciones de productos químicos y, más aún, por las materias primas e intermedias, cobra sentido a la luz

${ }^{31}$ Manejando los datos - poco fiables- de Ungewitter y del Anuario Aduanero de España, puede determinarse que los aranceles mínimos españoles eran a mediados de los años veinte de un 50 por 100 para productos químicos básicos, de más del 100 por 100 para colorantes, y del 10 por 100 para fertilizantes nitrogenados y medicamentos. Los principales cambios en los treinta estuvieron relacionados con la voluntad política de nacionalizar la manufactura de algunos productos químicos, para lo cual se intensificó la presión sobre los productos acabados, y se relajó para los intermedios. 
de la de las inversiones directas, la otra estrategia de crecimiento desplegada por las firmas alemanas. En la actuación de las firmas alemanas, igual que en las exportaciones, hemos detectado dos fases. Una primera, antes de la guerra, en la que apenas se buscó otra cosa que respaldar las ventas en el país con publicidad y asistencia técnica. $Y$ una segunda, en los años veinte $y$ treinta, en la que, para hacer frente a las barreras arancelarias, al proteccionismo industrial y a la inevitable difusión tecnológica, reforzaron y unificaron sus redes comerciales y adquirieron o ampliaron su participación en empresas locales.

La conquista del mercado español de colorantes sintéticos, constituido en dos tercios por la industria textil catalana, se hizo inicialmente por medio de representantes y agentes de las casas alemanas ${ }^{32}$. Estos trabajaban a comisión y vendían directamente a los fabricantes. Este procedimiento, que respondía al desconocimiento de las costumbres del país por parte de las centrales, se abandonó pronto en favor de la participación en sociedades españolas o la creación de filiales. Excepto Bayer, todos los fabricantes alemanes de colorantes que se establecieron en la Península antes de 1914 optaron por la primera opción. En ambos casos se trató de negocios modestos y estrictamente comerciales, pero muy útiles para familiarizarse con el mercado.

La pionera fue $\mathrm{BASF}^{33}$. En 1878 se había introducido en España a través de un representante, Sixto Quintana, que pudo mantener su independencia hasta 1911. Ese año, un colaborador suyo, Salvador Lluch, fundó Lluch y Cía., con otro socio catalán y dos alemanes, que representaban a la firma de Ludwigshafen. Para BASF, que exportaba más de un 70 por 100 de su producción, el español no constituía un mercado importante, pues, si bien se cuadruplicaron las ventas entre 1888 y 1913 , nunca supusieron más del 2 por 100 de las exportaciones mundiales. El ejemplo de BASF fue seguido, entre 1911 y 1912, por otras casas: AGFA, GriesheimElektron, Kalle, Hoechst, Cassella, Mühlheim/Leonhardt y Weiler-ter-Meer. La primera se asoció a la sociedad colectiva Asbert, Janot y Cía. ${ }^{34}$. La segunda buscó la colaboración de la sociedad anónima Comercial de Productos Químicos, fundada, entre otros, por el director de la Electro-Química de Flix, uno de los estandartes de la inversión industrial alemana en España desde $1897^{35}$. De Kalle sabemos sólo que se introdujo

32 BAL 110-1-35.

33 UA-BASF T001, «Geschichte der BASF 1885-1938».

34 RMB 1912, expediente número 8492, inscripción número 1, hoja número 66 .

35 RMB 1912, expediente número 8810, inscripción número 1, hoja número 196. 
en $1912^{36}$. Cassella lo hizo en el mismo año con Federico Serra, un representante experimentado de los intereses alemanes. Mühlheim-Leonhardt, con E. Portusach y Weiler-ter-Meer, participando en Bocatto SA. Éstos, como Jäger y Dahl, eran empresas pequeñas en España, y se colocaron pronto en la órbita de Bayer ${ }^{37}$. Aunque desde 1904 existían en Alemania dos «pequeñas IG», cuya misión era armonizar sus políticas de ventas y no hacerse la competencia, las denuncias mutuas de sus integrantes en España fueron constantes ${ }^{38}$.

Más interesante fue la creación de la filial Federico Bayer y Cía. en 1899. Según un informe de Willy Gansser, a la sazón viajante del departamento románico de la casa, Bayer se había introducido en España a mediados de los ochenta mediante representantes, pero el sistema no funcionaba bien, debido a querellas personales y a la falta de familiaridad con el entorno. A estos problemas vino a sumarse, en 1894 y 1895, la suspensión del acuerdo comercial hispano-alemán -la llamada «guerra comercial con Alemania»-, que hizo que se aplicaran los aranceles máximos. El éxito de las primeras filiales internacionales como instrumento para vencer barreras animó entonces a Bayer a crear una en Barcelona ${ }^{39}$. La filial catalana, muy modesta, funcionaba de acuerdo con la organización centralizada de la multinacional alemana y con el objetivo explícito de aumentar las ventas de los productos fabricados en Ėlberfeld ${ }^{40}$. Desde allí se ejercía el control sobre el grupo románico, integrado también por Italia y Portugal. Barcelona era a su vez la central española y, como todas las filiales de Bayer en el mundo, constaba de cuatro secciones (colorantes, farmaquímica, fotografía y primeras materias e intermedios) y dos directores, uno técnico y uno comercial. En 1907 contaba con 27 empleados, además de los directores. De ella dependían varias agencias provinciales.

La política de Bayer en España se centró en dos puntos: precios y calidad. Desde la central alemana se observaba con inquietud la guerra de precios que tenía lugar entre las casas alemanas representadas en Barcelona. El problema era común a todos los países clientes de la química alemana, y actuó como un poderoso motor para la conclusión de acuerdos entre las firmas alemanas. A diferencia de lo que ocurría en otros países

${ }^{36}$ RMB 1912, expediente número 8703, inscripción número 1, hoja número 24.

${ }^{37}$ Unicolor (1967), pp. 24-26.

38 BAL 110-1-35.

39 BAL 110-1-35.

*' Según el manuscrito de Gansser (1918), «Geschichte der Entwicklung der Farbenfabriken vorm. Friedr. Bayer \& Co. Elberfeld in den ersten 50 Jahren», pp. 369-380, BAL. 
europeos, sin embargo, los fabricantes locales en España no era una amenaza seria. Sólo uno, Vero Vidal, que fabricaba un color negro de excelente calidad a bajo precio, era mencionado por los informes de Bayer ${ }^{41}$. La calidad era el segundo eje de la actividad de Bayer en España. Pero los criterios para garantizarla eran distintos en la central y en Barcelona. Desde Alemania se defendían las marcas de los productos como principal arma de lucha contra la competencia, y con este argumento se desaprobaban las iniciativas del personal de la filial de emplear los molinos para mezclar los productos de la moderna planta de Leverkusen e imitar los colores de la competencia ${ }^{42}$. También la actividad del laboratorio se miraba con malos ojos, y se insistía en que su misión consistía en adiestrar a los técnicos, no en adaptar los colores a los gustos del mercado español. A pesar de su modestia, éste ganó peso en la actividad exterior de Bayer, que en 1913 vendía ya un 8,3 por 100 del total de sus exportaciones ${ }^{43}$. En la central confiaban en su crecimiento, tanto de colorantes como de otros productos.

Entre 1880 y 1913, así, la estrategia de las empresas químicas alemanas, cuyo negocio se apoyaba sobre todo en los colorantes sintéticos, consistió en controlar el mercado español por medio de representaciones, participaciones o filiales comerciales. Sus instrumentos fueron cuatro: precios descendentes; acuerdos de mercado con la competencia alemana; red comercial con asistencia técnica; y defensa de la calidad y las marcas. A través de ellos persiguieron un objetivo último, incrementar las exportaciones. $\mathrm{Y}$ este objetivo se logró con creces, de forma que la fabricación no entraba en los cálculos de los alemanes. El mercado español se repartía en 1913 así: Bayer 24,17 por 100, BASF 23,38 por 100, Cassella 19,59 por 100 , Hoechst 10,93 por 100 y Agfa 10,49 por $100^{44}$.

De los fabricantes españoles, sólo sabemos de uno que tuviera cierta importancia, Leopoldo Sagnier ${ }^{45}$. Bajo el nombre de Vero Vidal, este químico empezó a manufacturar colorantes sintéticos en 1881 en Sant Martí de Provençals. El negocio de Sagnier, como el de muchos industriales catalanes, cobró un impulso inesperado con la guerra mundial. La competencia tampoco se hizo esperar, y en el área de Barcelona surgieron cuatro empresas nuevas: Pellicer, Química Tarrasense, Graupera y Durán,

${ }^{41}$ BAL 10/3.1, 10/3.3, 11/3.1, 9/K.1, 1/6.6.18.2, 1/6.6.6.

42 BAL 110-1-35.

43 BAL 110-1-35.

${ }^{4} \mathrm{FAH} \mathrm{C} / 3 / 1 \mathrm{~b}$.

45 Cabana (1992), pp. 269-272, y BHI ZF «L. Sagnier. Diarios». 
y Marca y Otzet ${ }^{46}$. Para garantizar su supervivencia en tiempos de normalidad, y bajo la batuta de Leopoldo Sagnier, en 1923 se fundieron las cinco sociedades en una sola: Fabricación Nacional de Colorantes y Explosivos (FNCE).

La iniciativa catalana —oficialmente amparada por la Ley de 1917 de Protección a la Industria Nacional - tenía por objeto hacerse con el mercado español y ampliar progresivamente su programa de fabricación ${ }^{47}$. El proceso de creación de FNCE y los primeros pasos de la misma fueron seguidos con interés desde Bayer ${ }^{48}$. Pero la actividad de las casas suizas y de la competencia alemana suscitaba aún más temores. Los precios se habían duplicado, y resultaba muy difícil mantener los acuerdos de mercado previos a 1913 en el seno de las dos IG pequeñas. Las casas centrales se lamentaban además de la escalada arancelaria española desde 1919 y de la competencia de los españoles. Como en tantos otros sectores de la industria alemana durante el período de Entreguerras, en la química se pensó en fortalecer la política de acuerdos iniciada en 1904, y en 1924 se materializaron dos fusiones de gran trascendencia que, en Barcelona, se tradujeron en dos nuevas compañías comerciales, creadas a partir de las representaciones alemanas: Unión Química Comercial y Química Lluch ${ }^{49}$. Dos años más tarde se fundieron en la Unión Química y Lluch, la representación del nuevo consorcio químico alemáñ, la IG Farben, y el exponente de la nueva actitud con la que los industriales germanos afrontaban su negocio en el exterior. De forma paralela se crearon dos sociedades más para elaborar productos farmacéuticos y fotográficos, la Química Comercial Farmacéutica y AGFA-Foto ${ }^{50}$.

También en 1926, la IG entró a formar parte de su único competidor español claro, FNCE, adquiriendo el 50 por 100 de las acciones de la compañía e imponiendo la creación de un Comité Técnico que garantizaba el control de la producción por parte alemana ${ }^{51}$. Los socios españoles saludaron con tanto alivio como entusiasmo el acuerdo, pues los cuatro primeros años de vida de la compañía habían sido decepcionantes, y estaban buscando la asistencia técnica de un socio fuerte en Europa para sentar

${ }^{46}$ Anuario Industrial de Cataluña (1918). Sobre Pellicer, véase FTN, correspondència rebuda 1916.

${ }^{47}$ Lo que sigue sobre esta empresa procede de Puig (1999), razón por la cual se han reducido al máximo las referencias archivísticas.

tN BAL 67-3, 84-30, 126/6.

19 Unicolor (1967), pp. 26-30.

50 Unicolor (1967), pp, 26-30. Química Farmacéutica Bayer (1992).

s1 BHI BCN, Actas del Consejo de Administración, sesiones de 1926 y 1927. 
las bases de la química moderna en España. El acuerdo, sin embargo, estuvo acompañado de una serie de medidas que harían muy difícil cumplir esas expectativas. Para empezar, la comercialización de los productos, que era una parte esencial del negocio de los colorantes dentro y fuera de Alemania, se dejaba en manos de la Unión Química y Lluch. A este pacto se sumó otro que ligaría a FNCE a la otra gran empresa española del sector, Cros. De acuerdo con el mismo, FNCE arrendaba una fábrica de colorantes que la IG - a través de su participación en la Electro-Químicahabía construido en Flix durante la guerra, pero que nunca había llegado a funcionar, y Cros se comprometía a suministrar a FNCE primeras materias en condiciones favorables, y a no entrar en el campo de los colorantes. Muy poco después se firmó una alianza con la Unión Española de Explosivos, también con la mediación de la IG Farben y de la multinacional que tutelaba a la UEE, Kuhlmann. Se trataba de otro pacto de no injerencia en los ámbitos propios de ambas empresas, que frustraba un objetivo fundacional de FNCE de incorporar los explosivos a su programa de producción, y gravaba con un canon elevado sus beneficios futuros. Cloratita, otra sociedad creada por Cros y la IG en 1923 para producir explosivos, quedó inactiva en las mismas fechas, lo que hace pensar que formaba parte del mismo acuerdo. Los productos farmacéuticos quedaban excluidos del horizonte industrial de FNCE, en tanto en cuanto la Química Comercial Farmacéutica seguía actuando en España con socios exclusivamente alemanes. Y los productos fotográficos, por último, se inscribían en la órbita de AGFA.

Durante los diez años que siguieron a la entrada de los socios alemanes, FNCE se consolidó como una de las empresas más rentables del sector. Los beneficios de la «época alemana» animaron a los socios españoles de FNCE, que dominaban el Consejo de Administración, a diseñar planes de expansión muy ambiciosos. Sin embargo, el Consejo Técnico, controlado por los alemanes, y la propia central, los frenaban. Los planes consistian en avanzar en el proceso de integración hacia atrás, introduciendo los productos intermedios, tal como ocurría en todos los países donde la IG se había asociado a empresas locales, y en introducirse en algunos campos novedosos de la química orgánica, como los carburantes sintéticos, de la mano de los socios alemanes. La primera parte del plan encontró obstáculos en la IG, que no quería ceder uno de los pilares del negocio, y en las autoridades arancelarias españolas, que no se decidían a crear un sistema que propiciara la sustitución progresiva de importaciones. La segunda parte también se topó con las objeciones de los alemanes, que confiaban poco 
en las capacidades cientificas de sus socios y en las dimensiones del mercado interno, así como de la Administración española, que, a pesar del entusiasmo de los militares (o quizá precisamente por eso) por la gasolina sintética y la tecnología germana, no apoyó ni autorizó la iniciativa ${ }^{52}$. No obstante, el objetivo primario de FNCE de dominar el mercado español de colorantes sintéticos se cumplió sin demasiadas dificultades. Hasta el estallido de la guerra, la empresa catalana cubrió entre un 75 y un 80 por 100 de la demanda interna. El grueso de la producción correspondía a colores de consumo masivo, como los sofrales y azoicos. Los colores más modernos, más caros y de demanda más restringida, se importaban.

El negocio de la IG Farben en España estaba, pues, muy bien articulado. Se entiende así que la IG actuara como representante de España en algunos carteles internacionales. Los intereses del consorcio alemán eran en realidad mucho mayores de lo que los datos consignados en el Cuadro 5 puedan hacer pensar. Las filiales respaldaban con poco capital volúmenes muy considerables de ventas gracias a los suministros alemanes, con cuyos precios se regulaban los balances de estas empresas ${ }^{53}$. En las sociedades participadas, las primeras materias, sobrevaloradas, también se empleaban como reguladoras del negocio, que de este modo no dejaba beneficios en el país. El grueso de las ventas de la IG Farben en España siguió en los años treinta centrado en los colorantes y en los intermedios para colorantes. Le seguían en importancia los productos farmacéuticos y fotoquímicos. En comparación con las ventas mundiales del consorcio, los fertilizantes eran, en España, los grandes ausentes.

La Unión Química Lluch empezó a vender fertilizantes nitrogenados -el floranid de BASF- en 1925, pero no creó una sección específica de abonos hasta 1936, lo que da una idea de lo secundario de esta actividad $^{54}$. El mercado hispano estuvo entonces abierto a los grandes productores británicos y holandeses, que negociaban con la IG en el seno del cartel del nitrógeno, constituido en 1929. Esta situación enfrentó en España a los exportadores agrarios con los pocos industriales del nitrógeno locales ${ }^{55}$. Éstos denunciaban la falta de protección y el dumping de las multinacionales, algunas de las cuales - francesas y noruegas- estaban prestándoles apoyo técnico. Es comprensible que la IG no mostrara interés,

${ }^{2}$ Serrano y Mayorga (1929).

${ }^{53}$ Para la Química Comercial Farmacéutica, véanse BAL 9/K 1.2, 190/9.K.1.2.53 y AMAE R-9945. Para Agfa, AMAE R.4209 expediente 9.

${ }^{54}$ Unicolor (1967), pp. 36-39.

${ }^{55}$ Bustelo (1957), pp. 23-40. 


\section{CUADRO 5}

Inversiones de la industria química alemana en España en 1935

\begin{tabular}{l|c|c|c|c}
\hline Empresa espanola & $\begin{array}{c}\text { Año de } \\
\text { creación }\end{array}$ & $\begin{array}{c}\text { Capital social } \\
\text { (miles ptas. }\end{array}$ & $\begin{array}{c}\text { Participación } \\
\text { alemana }\end{array}$ & Actividad \\
\hline $\begin{array}{l}\text { 1. Fabricación Na- } \\
\text { cional de Coloran- } \\
\text { tes y Explosivos } \\
\text { (FNCE). }\end{array}$ & $1922-1926$ & 7.000 & $50 \%$ IG Farben & $\begin{array}{c}\text { Fabricación de co- } \\
\text { lorantes e inter- } \\
\text { medios. }\end{array}$ \\
\hline $\begin{array}{l}\text { 2. Unión Química y } \\
\text { Lluch (UQLL). }\end{array}$ & $1899-1925$ & 3.500 & $100 \%$ IG Farben & $\begin{array}{l}\text { Venta de coloran- } \\
\text { tes, productos } \\
\text { farmacéuticos y } \\
\text { fotográficos, y } \\
\text { fertilizantes. }\end{array}$ \\
\hline $\begin{array}{l}\text { 3. La Química Co- } \\
\text { mercial y Farma- }\end{array}$ & $1899-1925$ & 500 & $100 \%$ IG Farben & $\begin{array}{l}\text { Elaboración de pro- } \\
\text { ductos farmacéu- } \\
\text { ticos. }\end{array}$ \\
\hline $\begin{array}{l}\text { 4. Sociedad Electro- } \\
\text { química de Flix. }\end{array}$ & $1897-1926$ & 6.000 & $51 \%$ IG Farben & $\begin{array}{l}\text { Fabricación de pro- } \\
\text { ductos químicos. }\end{array}$ \\
\hline $\begin{array}{l}\text { 5. Cloratita. } \\
\begin{array}{l}\text { Linde. } \\
\text { 10. Abelló Oxigeno }\end{array}\end{array}$ & $1907-1922$ & 2.250 & $50 \%$ Linde & $\begin{array}{l}\text { Producción de oxi- } \\
\text { geno. }\end{array}$ \\
\hline $\begin{array}{l}\text { 6. AGFA-Foto. } \\
\text { cos Schering. }\end{array}$ & $1881-1925$ & 510 & $100 \%$ IG Farben & Elaboración de pro- \\
ductos fotográfi- \\
cos.
\end{tabular}

* Participación real. Entre 1930 y 1935, y presionadas por la legislación española, las filiales farmacéuticas nacionalizaron parcialmente, pero sólo en apariencia, su capital y consejo de administración.

FUENTE: AMAE, R-4309/7, R-4306/3, R-9945/2, R-10000/4, R-9942/4, R-9947/1, R-4209/9 y R-4302/4. 
antes de la guerra, por fabricar en España, y que rechazara sistemáticamente las invitaciones de sus socios españoles.

Para la industria farmacéutica, por el contrario, el campo estaba libre. $\mathrm{El}$ consumo de especialidades crecía rápidamente, los aranceles eran bajos, y la competencia local no constituía ninguna amenaza seria. El nacionalismo industrial sólo empezó a estrechar el cerco en 1931, al promulgarse la Ley de Especialidades Farmacéuticas, que obligaba a los «laboratorios» a registrarse y a elaborar las especialidades en España ${ }^{56}$. Esto hizo que la mayor parte de las representaciones comerciales se transformaran en laboratorios de confección y envasado, lo que provocó un incremento notable de las importaciones de sustancias farmacológicas. Las cuatro empresas farmacéuticas alemanas, Química Comercial Farmacéutica, Schering, Boehringer y Merck, adoptaron en los años treinta prácticas muy similares: manufacturaban, envasaban y distribuían especialidades a partir de las primeras materias importadas ${ }^{57}$. El negocio descansaba sobre dos pilares: las primeras materias y la llamada propaganda científica. De ésta, como de la supervisión de los laboratorios, se encargaban técnicos y médicos alemanes. Si bien las filiales farmacéuticas reportaron grandes beneficios, su adaptación al medio español supuso una penosa labor de aprendizaje. La comercialización se realizaba a través de una tupida red de visitadores médicos y de un cortejo sistemático a las farmacias. El caso más interesante es sin duda el de Schering ${ }^{58}$. Para esta firma berlinesa, España era en 1935 el segundo mercado internacional, después de Italia. Los preparados hormonales, la piedra angular de la investigación de Schering, se abrieron paso con gran facilidad en España, que desde Berlín se consideraba cabeza de puente hacia América Latina. Schering fue de hecho la única filial que diseñó un proyecto industrial, en vísperas de la guerra. El poder de mercado de la Química, por su parte, seguía residiendo en analgésicos como la aspirina y la cafiaspirina. Boehringer y Merck basaban su negocio, también boyante, en algunas especialidades de marca bien publicitadas. La creciente presión nacionalista tuvo también como efecto que las centrales alemanas

${ }^{56}$ La regulación del sector se había iniciado con el Real Decreto de 9 de marzo de 1924 , un reflejo tanto del nacionalismo farmacéutico como de los intentos de asimilar la normativa española a la europea.

57 AMAE R-9945 expediente 2 (Bayer), R-10.000 expediente 4 (Schering), R-9942 expediente 4 (Boehringer). Los expedientes de Merck en el AMAE no son accesibles, pero puede seguirse la pista de esta empresa en los de la Sociedad Electro-Química de Flix (R-9947 expediente 1) y AGFA (R-4209 expediente 9).

${ }^{58}$ SCH B-1 737/1 y B-6 1070. 
buscaran españoles de confianza para «nacionalizar» parcialmente los consejos de administración de sus filiales.

La penetración del fabricante de oxígeno Linde fue en apariencia sencilla ${ }^{59}$. La empresa familiar catalana Abelló se había establecido en 1907, y sólo competía con la Sociedad Española Carburos Metálicos, creada en 1897 con capital suizo, y la filial de la francesa L'Air Liquide, la Sociedad Española del Oxígeno, puesta en marcha en vísperas de la Gran Guerra. Abelló obtenía oxígeno por destilación del aire líquido, un procedimiento de Linde, que en 1922 adquirió el 50 por 100 del capital de Abelló. Esta empresa controlaba buena parte del mercado español (Cataluña y Valencia), y en 1924 empezó a prestar asistencia técnica a Carburos Metálicos.

Merece la pena mencionar, por último, la Industrial Resinera Ruth (IRRSA), una efímera asociación de los años veinte entre una empresa pionera, La Unión Resinera Española, y la compañía alemana Ruth ${ }^{60}$. La nueva empresa nació en el marco del proceso de integración vertical iniciado por el consorcio forestal e industrial vasco en Entreguerras, con el objeto de fabricar barnices y alcanfor sintético en Nueva Montaña con la asistencia técnica de Ruth. Se trataba de un proyecto ambicioso -que incluía un costoso laboratorio- pero inoportuno. Antes de cerrarse definitivamente, en 1927 se ofreció a Cros y a Schering, entre otros. Es bastante revelador que esta última lo rechazara aludiendo a la insuficiencia del mercado espanol y a la tendencia a la concentración de la industria internacional de la celulosa ${ }^{61}$.

Las inversiones químicas, como las de otros sectores de la industria alemana, tuvieron a su favor el entramado de las instituciones sociales y económicas alemanas en España. Las más relevantes fueron la filial del Deutsche Bank, el Banco Alemán Transatlántico, y la Cámara de Comercio $^{62}$. La colonia alemana, en el sentido más amplio, experimentó una expansión muy notable en los años veinte y treinta, especialmente en Barcelona. Sus relaciones con los empresarios y la burocracia locales fueron fluidas, preparando así el terreno a los artífices de la colaboración española con el nacionalsocialismo después de 1936. Hasta entonces, la inversión directa se convirtió en la más eficaz estrategia de crecimiento de la química

59 AMAE R-4302 expediente 4.

(x) Uriarte (1996), pp. 77-80.

${ }_{61} \mathrm{SCH}$ B 2-973/1.

${ }^{2}$ Viñas (1977) pp. 197-200 y 206-214. El Banco Hispano-Alemán, el Banco Alemán Transatlántico, la Cámara de Comercio y diversas sociedades económicas y culturales han sido analizados por Loscertales (1999), pp. 106-122 y pp. 283-286. 
alemana. Pero para el país receptor esta vía apenas contribuyó a la transferencia de tecnología y capacidades empresariales desde la primera potencia mundial.

\section{RESUMEN Y CONCLUSIONES}

La industria química orgánica alemana alcanzó su máximo esplendor entre 1880 y la Segunda Guerra Mundial. Los fundamentos de tal esplendor fueron las ventajas naturales, institucionales y de gestión empresarial que ofrecía el país, y que fueron aprovechadas plenamente por las empresas de colorantes sintéticos, líderes de la modernización del sector. La necesidad de explotar las economías de escala y de diversificación en las plantas alemanas hizo que las compañías intentaran maximizar las exportaciones. La difusión de medidas proteccionistas tras la guerra, después, les llevó a tratar de afianzarse en los países industriales o en proceso de industrialización para dar salida a su producción. Esta inversión directa adoptó con frecuencia la forma de participación o colaboración con empresas nacionales. Mientras éstas trataban de avanzar en el proceso de sustitución de importaciones gracias a la asistencia técnica de los alemanes, éstos controlaban tal proceso en función de los intereses de sus compañías y garantizaban un nivel importante de exportaciones de productos — cada vez más diversos- de las fábricas alemanas.

El caso español es representativo de las estrategias de crecimiento de las empresas alemanas entre 1880 y 1936 . Hasta 1913, los colorantes sintéticos adquirieron una posición dominante en el mercado español, y abrieron el camino a otros productos de la química germana, como los fertilizantes y los fármacos. Después de la guerra, los empresarios que habian crecido o surgido al calor de la misma solicitaron protección a los poderes públicos, lo que se tradujo en diversas ventajas —derivadas de la legislación industrial- para las empresas locales y, sobre todo, elevados aranceles para colorantes. Los fertilizantes nitrogenados quedaban por el contrario privados de protección, lo que abrió el mercado español al sindicato internacional del nitrógeno, donde estaban bien representados los alemanes. En cambio, la legislación farmacéutica tendió a nacionalizar la fase final de la fabricación de fármacos, favoreciendo así la inversión directa y la familiarización de las firmas alemanas con el mercado español, una ventaja indiscutible en el largo plazo. Los efectos de la protección fueron, pues, menos negativos para los intereses alemanes de lo que éstos habían temido. 
Su columna vertebral, la exportación de colorantes, logró recuperarse y mantenerse en niveles bastante altos, mientras se incrementaron sustancialmente las ventas de fertilizantes sintéticos, especialidades farmacéuticas $\mathrm{y}$, sobre todo, productos intermedios para la manufactura de colorantes y fármacos.

La trayectoria de las empresas mixtas revela algunos de los efectos del proteccionismo arancelario e industrial de Entreguerras. Cuando la IG Farben se convirtió en socia del primer fabricante español de colorantes, FNCE, la posición absoluta y relativa de Alemania como proveedora de colorantes empeoró sensiblemente, pero las exportaciones de colorantes complejos y de productos intermedios, en cambio, se incrementaron de forma muy notable. Esto era un proceso común a otros países en los que la IG adquirió participaciones para salvar los aranceles y otras trabas del nacionalismo industrial de la época. Pero, como los fabricantes españoles no lograron el apoyo técnico y financiero preciso para la diversificación que habían esperado al aliarse con los alemanes, muchas de las otras exportaciones pudieron realizarse con gran libertad. El pacto IG-FNCE de 1926, en efecto, frustraba tres vías esenciales de crecimiento de la empresa espanola: la comercialización, que quedaba en manos de la IG; la producción de explosivos, reservada a la poderosa UEE; y la fabricación de diversos intermedios, que se subordinaba a los intereses de Flix/Cros. La farmaquímica y la fotoquímica, dos campos de interés creciente para la IG, quedaban reservadas a las filiales españolas del consorcio. La estrategia de las empresas farmacéuticas no integradas en la IG Farben era muy similar a la de estas filiales: los establecimientos españoles confeccionaban o envasaban productos importados de Alemania a precios extraordinariamente elevados. La presencia alemana en el campo de los fertilizantes fue, en cambio, tardía y débil, y circunscrita además al ámbito comercial. Existían poderosos carteles internacionales que desaconsejaban la inversión industrial en España, y ésta contaba además con una industria de superfosfatos nada desdeñable. La industria alemana del oxígeno entró en España de la mano de Linde, que, con la familia Abelló, se aseguró una posición fuerte en el mercado español. La breve experiencia de IRRSA, por último, muestra las limitaciones que el mercado español e internacional imponía a este tipo de sociedades.

La gran diferencia entre España y otros países que en vísperas de la Gran Guerra ocupaban posiciones periféricas en la industria química mundial, no radica sólo en la estrategia de las empresas alemanas, sino en la de los socios y competidores locales. Además de que España no lograra 
la autosuficiencia en campos como los colorantes, y de que países como Italia o Japón aumentaran su producción a un ritmo diez veces superior al de España, llama la atención que ni en éste ni en otros subsectores el programa de fabricación se ampliara sustancialmente, y que no hubiera transferencia tecnológica en sentido estricto. El menor desarrollo económico de España, y las menores dimensiones del mercado nacional, sólo lo explican parcialmente. En los casos en que hubo colaboración con empresas españolas, los inversores alemanes pudieron imponerse sin demasiadas dificultades. En este sentido, España no es plenamente comparable con Italia, cuyos industriales tenían varias cosas a su favor: una infraestructura científica (bien representada por el Politécnico de Milán), que hizo posible la actividad investigadora e innovadora de Fauser; una protección arancelaria adecuada desde 1921, a partir de 1934 intensificada por el proyecto autárquico del fascismo; y un interlocutor influyente, Montecatini, para negociar con sus socios alemanes y cooperar también en el campo de la investigación. El menor desarrollo y mayor dispersión de la química espanola fueron aprovechados hábilmente por la IG Farben para evitar algo similar en España, lo que acerca a este país a experiencias como las de Polonia.

La moderna industria química requería inversiones de envergadura en enseñanza e investigación y desarrollo. Los pocos estudios sobre infraestructura científica y organización industrial publicados hasta el momento invitan a pensar que el nacionalismo económico español apenas se ocupó de este aspecto crucial de la industrialización química, que seguiría constituyendo una poderosa barrera para los empresarios españoles, y una ventaja para los alemanes. Si bien aquéllos se mostraron receptivos a los cambios y a las oportunidades de los mercados, no realizaron avances notables en las líneas sobre las que progresaba la química: la investigación y el desarrollo, la comercialización y la organización empresarial. Las empresas mixtas, una vez más, dan la clave.

\section{BIBLIOGRAFÍA}

\section{ANUARIOS Y PUBLICACIONES PERIÓDICAS}

AFINIDAD (1921-1936): Barcelona, Instituto Químico de Sarrià. ANUARIo AduAnero de España (1931 y 1934): Madrid, Rivadeneyra. ANuARIo de Industrias QuimiCAS (1932): Barcelona, Cámara Nacional de Industrias Químicas. 
Anuario Financiero y de Sociedades Anónimas (1916-1935): Madrid.

Anuario Industrial de Cataluña (1918, 1923 y 1934): Barcelona, Cámara Oficial de Industria de Barcelona.

Die Chemische Industrie. Organ für die Berufsgenossenschaft der chemischen Industrie (1890-1935).

Estadística del COMERCio EXTERIOR de EsPaña (1913-1935).

Química e InDUSTRIA: Barcelona, 1924-1937. Órgano oficial de la Cámara Nacional de Industrias Químicas desde abril de 1925.

Statistik des Deutschen Reiches. AuswärtTger Handel (1880-935): Berlin, Kaiserliches Statistisches Amt.

\section{LIBROS, ARTÍCULOS E HISTORIAS CONMEMORATTVAS}

Abramovitz, Moses (1986): «Catching Up, Forging Ahead, and Falling Behind», Journal of Economic History, XLVI, 2, pp. 385-406.

Amatori, Franco, y Bezza, Bruno (eds.) (1990): Montecatini 1888-1966. Capitoli di storia di una grande impresa, Bologna, Fondazione Assi-il Mulino.

Arora, Ashish; Landau, Ralph, y RosenberG, Nathan (eds.) (1998): Chemicals and long-term Economic Growth: Insights from the Chemical Industry, New York, John Wiley-Chemical Heritage Foundation.

BADISCHE ANILIN y SODAFABRIK (1990): Hundertfünfundzwanzig Jabre BASF. Stationen ibrer Geschichte, Ludwigshafen.

BAYER AG (1988): Milestones. The Bayer Story 1863-1988, Leverkusen, Bayer AG.

BuSTELO, Francisco (1957): «Notas y comentarios sobre los orígenes de la industria española del nitrógeno», Moneda y Crédito, 63, pp. 23-40.

Cabana, Francesc (1992): Fàbriques $i$ empresaris. Els protagonistes de la revolució industrial a Catalunva. Quimics i metal. luirgics, Barcelona, Enciclopèdia Catalana.

Carreras, Albert (coord.) (1989): Estadísticas históricas de España. Siglos XIX-XX, Madrid, Fundación Banco Exterior.

Chandler, Alfred D. (1990): Scale and Scope. The Dynamics of Industrial Capitalism, Cambridge-London, Belknap-Harvard.

Comín, Francisco (1997): «El Estado, la rigidez de los mercados y la convergencia en el siglo XX», VI Congreso de la Asociación de Historia Económica, Girona, Sesiones plenarias, pp. 49-61.

Comisión Protectora de la Producción Nacional (1918): Memoria reglamentaria, 2 vols., Madrid, S. E. de Artes Gráficas.

- (1924): Acta de la última sesión celebrada por su Comité Ejecutivo y resumen de su labor en los dos últimos años, Madrid, S. E. de Artes Gráficas.

Consejo de ECONOMía NACIONAL (1924, 1925 y 1927): Memoria de la actuación de la Comisión de Economía Nacional, Madrid, Imprenta Z. Ascasíbal y Cía.

GALI, Alexandre (1981): Historia de les institucions $i$ del moviment cultural a Catalunya 1900-1936, Fundació A. Galí, Barcelona.

GoERTZ, Gary (1990): The World Chemical Industry around 1910. A comparative analysis by branch and country, Geneva, Centre of International Economic History. 
HABER, Lutz F. (1958): The Chemical Industry during the Nineteenth Century. A Study of the Economic Aspects of Applied Chemistry in Europe and North America, Oxford, Clarendon Press.

- (1971): The Chemical Industry 1900-1939. International Growth and Technological Change, Oxford, Clarendon Press.

Haynes, William (1945-1954): The American Chemical Industry (6 vols.), Toronto-New York-London, D. van Nostrand Company, Inc.

HERTNER, Peter, y JONES, Geoffrey (eds.) (1986): Multinationals : theory and bistory, Aldershot, Gower.

HoECHST AG. (1990): Chronik der Hoechst Aktiengesellschaft 1863-1988, Frankfurt, Hoescht AG.

JONES, Geoffrey, y SCHröter, Harm G. (eds.) (1993): The Rise of Multinationals in Continental Europe, Aldershot, Edward Elgar.

KudO, Akira (1994): «IG Farben in Japan: The Transfer of Technology and Managerial Skills», Business History 36, pp. 159-183.

LeaGue OF NATIONS (1947): International Cartels. A League of Nations Memorandum, New York, United Nations Organisation.

LOSCERTALES, Javier (1999): «Deutsche Investitionen in Spanien, 1880-1920», Tesis Doctoral, J. W. Goethe Universität, Frankfurt a. M.

Muñoz, Pere (coord.) (1997): Centenario de «La Fábrica». De la Sociedad Electro-Química de Flix a Erkimia 1897-1997, Barcelona, Ercros.

NADAL, Jordi (1986): «La debilidad de la industria química española durante el siglo XIX. Un problema de demanda», Moneda y Crédito 186, pp. 33-70.

- (1993): «La consolidació pel biaix dels adobs. 1914-1939», Història econòmica de la Catalunya contemporània, 6, Barcelona, Enciclopèdia Catalana, pp. 149-166.

PETRI, Rolf (1998): «Technical change in the Italian chemical industry. Markets, firms and State intervention», en Travis et al. (eds.), pp. 275-300.

Plumpe, Gottfried (1990): Die IG Farbenindustrie AG. Wirtschaft, Technik, Politik 1904-1945, Berlin, Dunker \& Humblot.

Pollard, Sidney (1991): La conquista pacífica. La industrialización de Europa, 1760-1970, Zaragoza, Prensas Universitarias de Zaragoza.

PuIG, Nuria (1998): «The frustrated rise of Spanish chemical industry between the wars», en Travis et al. (eds.): pp. 301-320.

- (1999): «Los orígenes de una multinacional alemana en España: Fabricación Nacional de Colorantes y Explosivos, 1881-1965», Documento de Trabajo 9904, Programa de Historia Económica, Fundación Empresa Pública.

Puig Raposo, Nuria, y López Garcí, Santiago (1992): Ciencia e industria en España. El Instituto Químico de Sarrià (1916-1992), Barcelona, Institut Químic de Sarrià.

- (1994): «Chemists, Engineers and Entrepreneurs. The Chemical Institute of Sarrià's Impact on Spanish Industry (1916-1992)», History and Tecbnology, 11, pp. 345-359.

Química Farmacéutica Bayer (1992): Apuntes para una bistoria de Quimica Farmacéutica Bayer, S. A., Barcelona.

READER, William J. (1970, 1975): Imperial Chemical Industries: A History (2 vols.), London, Oxford University Press. 
SCHRÖTER, Harm G. (1987): «Kartelle als Form industrieller Konzentration: Das Beispiel des internationalen Farbstoffkartells von 1927 bis 1939», Vierteljahrschrift für Sozial- und Wirtschaftsgeschichte, 74, 4, pp. 479-513.

- (1990): «Die Auslandsinvestitionen der deutschen chemischen Industrie 1870 bis 1930», Zeitschrift für Unternebmensgeschichte, 35, pp. 1-22.

Serrano, César, y MayorGa, Antonio (1929): Sintesis de los compuestos nitrogenados. Hidrogenación de los carbones. Informe sobre la obtención del nitrógeno y sus derivados, Madrid, Compañía General de Artes Gráficas.

Sociedad Electro-Quimica de Flix (1966): Historia de Electro-Quimica de Flix, S. A., 1897-1965, Barcelona.

Suárez InClá, Félix (1922): Industrias esenciales. Organización económica del Estado, Madrid, Imprenta de R. Velasco.

Travis, Anthony S.; Schröter, Harm G.; Homburg, Ernst, y Morrus, Peter J. T. (eds.) (1998): Determinants in the Evolution of the European Chemical Industry, 1900-1939: New Technologies, Political Frameworks, Markets, and Companies, Dordrecht, Kluwer.

TORTELla, Gabriel (1983): «La primera gran empresa química española: la Sociedad Española de la Dinamita (1872-1896)», Historia económica y pensamiento social. Homenaje a Diego Mateo del Peral, Madrid, Alianza, pp. 431-453.

- (1987): «La implantación del monopolio de explosivos en España», Hacienda Pública Española (Homenaje a Don Ramón Carande), 108-109, pp. 393-410.

- (1992): «La integración vertical de una gran empresa española durante la dictadura de Primo de Rivera. La Unión Española de Explosivos, 1917-1929», en García Delgado (coord.), Economía española, cultura y sociedad. Homenaje a Juan Velarde Fuertes, Madrid, Eudema, pp. 359-393.

UnGEWTTTER, Claus (1927): The Chemical Industry, Geneva, League of Nations. - (1931), Die grossen Chemie-Konzerne Deutschlands 1931, Berlin, Das Spezial-Archiv der deutschen Wirtschaft.

UNICOLOR (1967): Historia de Unicolor, Barcelona, La Poligrafa.

URIARTE AyO, Rafael (1996): «La Unión Resinera Española (1898-1936)», Documento de Trabajo 9610 del Programa de Historia Económica de la Fundación Empresa Pública, Madrid.

U. S. Department of Commerce (1933): The European Chemical Industry in 1932, Washington, Government Printing Office.

VICENS I VIVES, Jaume (1958): Industrials i politics (segle XIX), Barcelona, Vicens Vives.

ViÑAs, Angel (1977): La Alemania nazi y el 18 de julio, Madrid, Alianza.

ZAMAGNI, Vera (1990): «L'industria chimica in Italia dalle origini agli anni'50», en Amatori y Bezza, pp. 69-148.

\section{FUENTES}

Archivo del Ministerio de Asuntos Exteriores (AMAE).

ArXiu del Foment del Treball Nacional (AFTN).

Bayer Archiv Leverkusen (BAL). 
Bayer Hispania Industrial Barcelona (BHI BCN).

Bayer Hispania Industrual Zona Franca (BHI ZF).

Firmenarchiv der HoEchst AG Frankfurt (FAH).

Registro MeRCANTIL dE BarCelona (RMB).

SCheringianum Berlin (SCH).

UnternehmensarChIV der Badischen Anilin- \& Sodafabrik Ludwigshiafen am RIIEIN (UA-BASF). 